\title{
NBSIR 82-2512
}

\section{A Computer Program for Analysis of Smoke Control Systems}

U.S. DEPARTMENT OF COMMERCE

National Bureau of Standards

National Engineering Laboratory

Center for Fire Research

Washington, DC 20234

June 1982

Final Report

Sponsored in part by:

$Q C$

100

456

$32-2512$

1982

c. 2

\section{zpartment of Health and Human Services} ashington, DC 20201 



\section{A COMPUTER PROGRAM FOR ANALYSIS OF SMOKE CONTROL SYSTEMS}

John H. Klote

U.S. DEPARTMENT OF COMMERCE

National Bureau of Standards

National Engineering Laboratory

Center for Fire Research

Washington, DC 20234

June 1982

Final Report

Sponsored in part by:

Department of Health and Human Services

Washington, DC 20201

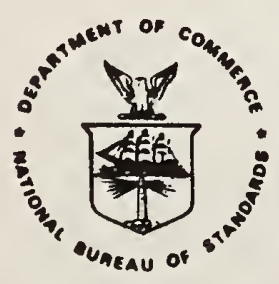

U.S. DEPARTMENT OF COMMERCE, Malcolm Baldrige, Secretary NATIONAL BUREAU OF STANDARDS, Ernest Ambler, Director 
$\therefore \quad \therefore 4=4 \%=$

, fir :

i. $\quad \cdots$

i. 
This report is an interim product of a joint effort of the Department of Health and Human Services and the National Bureau of Standards (NBS), Center for Fire Research. The program is a multi-year activity initiated in 1975. It consists of projects in the areas of: decision analysis, fire and smoke detection, smoke movement and control, automatic extinguishment, and behavior of institutional populations in fire situations.

This report describes a computer program which analyzes pressurized stairwells and pressurized elevators. The program was initially intended as a research tool to investigate the feasibility of specific systems. However, this program may be of interest to design engineers responsible for pressurized stairwells or pressurized elevators. 


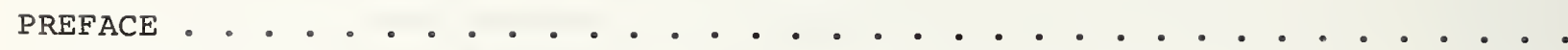
Page IIST OF FIGURE

1. INTRODUCTION

2. PROGRAM CONCEPT . . . . . . . . . . . . . . . . . . . . . . . . . . . . . . . .

3. ASSUMPTIONS AND LIMITATIONS . . . . . . . . . . . . . . . . . . . . . . 3

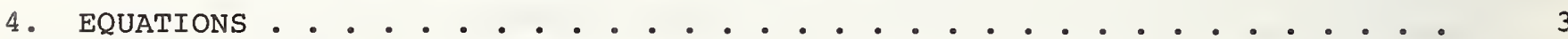

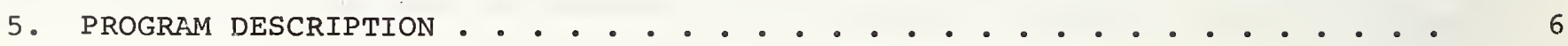

5.1 Main Program . . . . . . . . . . . . . . . . . . . . . . 7

5.2 INPUT Subroutine . . . . . . . . . . . . . . . . . . . . . . . . . . 7

5.3 CORR Subroutine

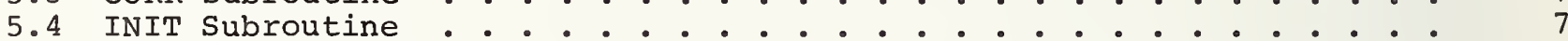

5.5 BLDGP Subroutine . . . . . . . . . . . . . . . . . . . . . . . .

5.6 SHAFTP Subroutine . . . . . . . . . . . . . . . . . . . . . . . . . . . .

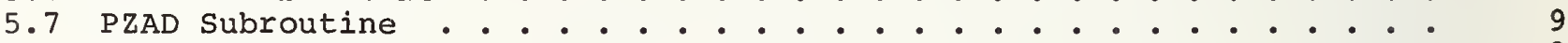

5.8 OUT Subroutine . . . . . . . . . . . . . . . . . . . . . . . . . . 9

6. FUTURE DIRECTION . • . . . . . . . . . . . . . . . . . . . . . . . 9

7. REFERENCES •. . . . . . . . . . . . . . . . . . . . . . . . . . . 0

APPENDIX A. DATA INPUT DESCRIPTION FOR COMPUTER PROGRAM . . . . . . . . . II

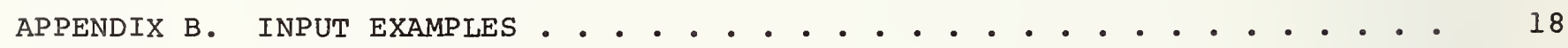

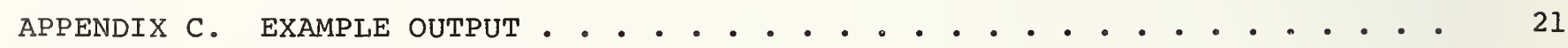

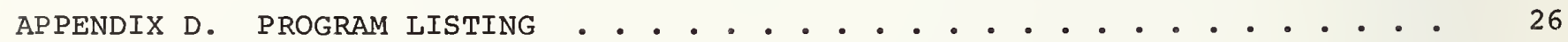




\section{LIST OF FIGURE}

Figure 1. Flow chart for main program . . . . . . . . . . . . . . . 

John H. Klote

\begin{abstract}
This paper describes a computer program developed to analyze systems intended to control smoke in building fires. These systems include pressurized stairwells, pressurized elevator shafts, zone smoke control systems, and pressurized corridors. This program calculates air flows and differential pressures throughout a building in which a smoke control system is operating. The basic assumptions and limitations of the program are also discussed. The appendices contain a program listing and examples.
\end{abstract}

Key words: Air movement; computer programs; egress; elevator shafts; escape means; modeling; pressurization; simulation; smoke control; stairwells.

\title{
1. INTRODUCTION
}

The majority of fire fatalities result from smoke inhalation. As a result of this, a number of systems have been designed and built to control smoke movement in building fires. The most common smoke control systems are pressurized stairwells and zone smoke control systems ${ }^{l}$. These systems are intended to control smoke movement in a building by use of air flows and by differential pressures. The computer program described in this paper provides a means to calculate the air flows and differential pressures throughout a building (either real or conceptual) in which a smoke control system is operating.

A number of computer programs have been developed which are applicable to smoke control. Some of these programs calculate steady state air flow and pressures throughout a building $[1,2]^{2}$. Other programs go beyond this to calculate smoke concentrations throughout a building that would be produced in the event of a fire [3-7]. In general, most of these programs are capable of analyzing smoke control

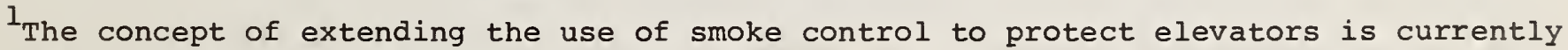
being investigated at NBS.

${ }^{2}$ Numbers in brackets refer to the literature references listed at the end of this paper.
} 
systems. However, the program described in this paper has been specifically written for analysis of smoke control systems and is an extension of a program specifically written for analysis of pressurized stairwells and elevators [8]. While the basic theory of this program is the same as that of the stairwell program it has been extended to include analysis of (1) stairwells with vestibules, (2) elevators with elevator lobbies, (3) zone smoke control systems, and (4) pressurized corridors. The data input has been designed to minimize the quantity of required data and still maintain a high level of generality in the model. The output consists of the pressure differences across all of the building shafts, as well as the flows and pressures throughout the building.

This program was originally intended primarily as a research tool to investigate the feasibility of specific smoke control systems and to determine the interaction between these systems and the rest of the building. The predecessor [8] of this program has already been used to analyze pressurized stairwells without vestibules and to evaluate factors which affect the performance of these systems [9]. And, this program has been used to generate data for an National Bureau of Standards (NBS) Handbook on Smoke Control Design which is being developed. This paper is not intended to be a design guide for smoke control systems. The state-of-the-art of these systems is still under development and designers of these systems should seek the most current data available.

\section{PROGRAM CONCEPT}

In this computer program a building is represented by a network of spaces or nodes each at a specific pressure and temperature. The stairwells and other shafts are modeled by a vertical series of spaces, one for each floor. Air flows through leakage paths from regions of high pressure to regions of low pressure. These leakage paths are doors and windows which may be opened or closed. Leakage can also occur through partitions, floors, exterior walls and roofs. The air flow through a leakage path is a function of the pressure difference across the leakage path.

In this computer model air from outside the building can be introduced by a pressurization system into any level of a shaft or even into other building spaces. This allows simulation of stairwell pressurization, elevator shaft pressurization, stairwell vestibule pressurization, and pressurization of any other building space. In addition, any building space can be exhausted. This allows analysis of zone smoke control systems where the fire zone is exhausted and other zones are pressurized. The pressures throughout the building and flow rates through all the flow paths are obtained by solving the air flow network including the driving forces such as the wind, the pressurization system or an inside to outside temperature difference. 


\section{ASSUMPTIONS AND LIMITATIONS}

1. Each space is considered to be at one specific pressure and one specific temperature.

2. The flows and leakage paths are assumed to occur at mid-height of each level.

3. The net air supplied by the air handling system or by the pressurization system is assumed to be constant and independent of building pressure.

4. The outside air temperature is assumed to be constant.

5. The barometer pressure at ground level is assumed to be standard atmospheric pressure $\left(101325 \mathrm{~Pa}^{3}\right.$.

\section{EQUATIONS}

A. Flow equation

$$
F=C A \sqrt{2 \rho \Delta P}
$$

where:

$F=$ mass flow rate

$\mathrm{C}=$ flow coefficient

$A=$ flow area

$\rho=$ density of air in flow path

$\Delta \mathrm{P}=$ pressure difference across flow path

The flow coefficient is dimensionless and for smoke control analysis it is generally taken to be in the range of 0.6 to 0.7 . Because of the large number of flow calculations performed during the computer analysis the flow equation is rewritten in the program as $F=C^{\prime} \sqrt{\Delta \mathrm{P}}$. Using the ideal gas law, the adjusted flow coefficient, $C^{\prime}$, can be expressed as

$$
C^{\prime}=C A \sqrt{\frac{2 P_{a t m}}{R T}}
$$

where:

$$
\begin{aligned}
\mathrm{P}_{\mathrm{atm}} & =\text { absolute barometric pressure at ground level } \\
\mathrm{R} & =\text { gas constant of air } \\
\mathrm{T} & =\text { absolute temperature of air in flow path }
\end{aligned}
$$

3 The results of the program are not very sensitive to changes in atmospheric pressure. For altitudes considerably different from sea level the more accurate value can be substituted by changing an assign statement in the subroutine INPUT and one in the subroutine CORR. 
B. Mass Balance Equations

For building compartment ${ }^{4}$ i

$$
\sum_{j=1}^{N_{C}} F_{(i, j)}+\sum_{k=1}^{N_{O}} F_{o(i, k)}+F_{f(i)}=0
$$

and for shafts

$$
\sum_{i=N_{1}}^{N_{2}}\left[\sum_{j=1}^{N_{C}} F_{(i, j)}+\sum_{k=1}^{N_{O}} F_{\circ(i, k)}+F_{f(i)}\right]=0
$$

where:

$$
\begin{aligned}
& F_{(i, j)}=\text { mass flow rate from space } j \text { to space } i \text {. For building } \\
& F_{\circ(i, k)}=\underset{\text { mass flow rate from direction } k \text { outside of the building }}{\text { to space } i \text {. }} \\
& \begin{aligned}
& F_{(i)}= \text { net mass flow rate of air due to the air handing system } \\
& \text { or due to a pressurization system. }
\end{aligned} \\
& \mathrm{N}_{\mathrm{C}} \text { = number of building spaces connected to space } i \text {. } \\
& \mathrm{N}_{\mathrm{O}}=\text { number of connections to the outside from space } i \text {. }
\end{aligned}
$$

$\mathrm{N}_{1}$ is the space number at the bottom level of the shaft and the spaces in the shaft are numbered consecutively up to $\mathrm{N}_{2}$ which is the space number at the top of the shaft.

\section{Shaft Pressures}

The following relationship is used to calculate the gage pressure, $\mathrm{P}_{(i)}$ ' at floor $i$ of a shaft in terms of $P_{(i-1)}$ at floor $i-1$.

$$
P_{(i)}=P_{(i-1)}-P_{z}-P_{f}
$$

where:

$\mathrm{P}_{\mathrm{z}}=$ hydrostatic pressure difference

$\mathrm{P}_{\mathrm{f}}=$ pressure loss due to friction

The following equation is used to calculate the hydrostatic pressure difference.

${ }^{4}$ In this paper the term building compartment refers to a space in a building other than in a shaft. 


$$
\mathrm{P}_{z}=\frac{\mathrm{g} \overline{\mathrm{P}}}{\mathrm{R} \overline{\mathrm{T}}} \quad \mathrm{h}_{(i)}-\mathrm{h}_{(i-1)}
$$

where:

$$
\begin{aligned}
\mathrm{h}_{(i)} & =\text { height of point } i \\
\mathrm{~h}_{(i-1)} & =\text { height of point } i-1 \\
\mathrm{~g} & =\text { gravitational acceleration } \\
\mathrm{R} & =\text { gas constant } \\
\overline{\mathrm{T}} & =\frac{\mathrm{T}(i)+\mathrm{T}(i-1)}{2} \\
\overline{\mathrm{P}} & =\frac{\mathrm{P}_{(i)}+\mathrm{P}_{(i-1)}}{2}+\mathrm{P}_{\mathrm{b}}
\end{aligned}
$$

$\mathrm{P}_{\mathrm{b}}$ is a constant used to convert an average gage pressure to the average absolute pressure, $\overline{\mathrm{P}}$.

The following equation is used to calculate the pressure loss due to friction.

$$
\mathrm{P}_{\mathrm{f}}=\mathrm{s}\left(\frac{\dot{\mathrm{m}}_{\mathrm{u}}}{\mathrm{C}_{\mathrm{s}}}\right)^{2}
$$

where:

$$
\begin{aligned}
\dot{\mathrm{m}}_{\mathrm{u}} & =\text { upward flow from } i-1 \text {. to } i \text { in shaft } \\
\mathrm{C}_{\mathrm{S}} & =\text { shaft flow coefficient } \\
\mathrm{S} & =\text { sign of } \dot{\mathrm{m}}_{\mathrm{u}}
\end{aligned}
$$

\section{Outside Pressures}

Outside pressures can either be entered by the user or can be calculated by the following method.

$$
P_{o(i)}=P_{h(i)}+C_{w} P_{v(i)}
$$

where:

$\mathrm{P}_{\mathrm{o}(i)=}$ outside gage pressure at height $\mathrm{h}(\mathrm{i})$ above absolute pressure

${ }^{P_{h}(i)}=$ hydrostatic pressure difference between $h(i)$ and ground level

$\mathrm{P}_{\mathrm{V}(i)}=$ velocity pressure due to the wind at height $\mathrm{h}(\mathrm{i})$

$\mathrm{C}_{\mathrm{w}}=$ pressure coefficient

Because the outside temperature is constant

$$
P_{h(i)}=P_{a t m} \exp \left(-\frac{g h(i)}{R T \text { out }}\right)-P_{b}
$$


where:

$\mathrm{P}_{\text {atm }}=$ absolute barometric preisire at ground level

$\mathrm{T}_{\text {out }}=$ outside absolute temperature

When the outside pressures are calculated by the computer the wind velocities are assumed to be described by the power law.

$$
v=v_{0}\left(\frac{h}{h_{0}}\right)^{n}
$$

where:

$$
\begin{aligned}
\mathrm{v}_{0} & =\text { wind velocity at height } \mathrm{h}_{0} \\
\mathrm{n} & =\text { wind exponent }
\end{aligned}
$$

This relationship has been extensively used to describe the boundary-layer velocity profile of the wind near the surface of the earth. It assumes that the terrain surrounding the building is homogeneous. That is, that there are no large obstructions near the building which could produce local wind effects. A value of 0.16 for the wind exponent is appropriate for flat terrain. The wind exponent increases with rougher terrain. For very rough terrain such as urban areas a value of 0.40 would be appropriate.

The equation for the velocity pressure at height $h(i)$ is obtained by substituting the velocity from the power law into the usual relation for velocity pressure $\left(P_{V}=\right.$ $\left.\frac{1}{2} \rho v^{2}\right)$.

$$
P_{v}=\frac{\rho v_{o}^{2}}{2}\left(\frac{h(i)}{h_{0}}\right)^{2 n}
$$

where $\rho$ is the outside air density.

The pressure coefficients are in the range of -0.8 to 0.8 where positive values are for windward walls and negative values are for leeward walls. The $z$ pressure coefficient depends upon building geometry and varies locally over the wall surface. Numerical values for $\mathrm{C}_{\mathrm{w}}$ and $\mathrm{n}$ as well as practical engineering information are available from a number of sources [10-13].

\section{PROGRAM DESCRIPTION}

This program is written in ANSI FORTRAN on the UNIVAC 1100/82 and a program listing is provided in appendix D. The following is a detailed description of the main program and the major subroutines. 


\subsection{Main Program}

The main program calls the subroutines which read the data, calculate the adjusted flow coefficients, calculates the initial values of pressures and interatively solves for the pressures according to the logic illustrated in the flow chart of figure 1 .

\subsection{INPUT Subroutine}

This routine reads the data that are necessary for a flow analysis of the stairwell or elevator, including an analysis of the rest of the building. These data consist of the following:

1. Outside temperature.

2. Temperature throughout the building.

3. Outside pressures. These can be entered or calculated as described earlier.

4. Description of the flow network including flow coefficients and flow areas for all connections and the net air flows to each space due to the air conditioning system or due to a pressurization system.

The data above can be entered in either SI units or in engineering units. Appendix A contains a detailed description of the data input method.

In addition to reading data, this subroutine provides temperature and pressure data as well as a complete description of the flow network. This routine also calculates initial estimates of the hydrostatic pressure differences. When data is entered in engineering units the subroutine UNITS is called which converts all units to the SI system.

\subsection{CORR Subroutine}

This routine calculates adjusted flow coefficients for all flow paths using eq. (3.2). Two sets of these coefficients are calculated for each flow path to allow for flow in either direction.

\subsection{INIT Subroutine}

This routine calculates initial estimates of the building pressures by a technique used by sander [1]. In this technique, mass flows are considered linear functions of differential pressure and therefore the flow equations can be expressed and solved in matrix form. In this estimate, shaft pressures are considered hydrostatic. The resulting pressures form a starting point for the iterative solution which follows. 


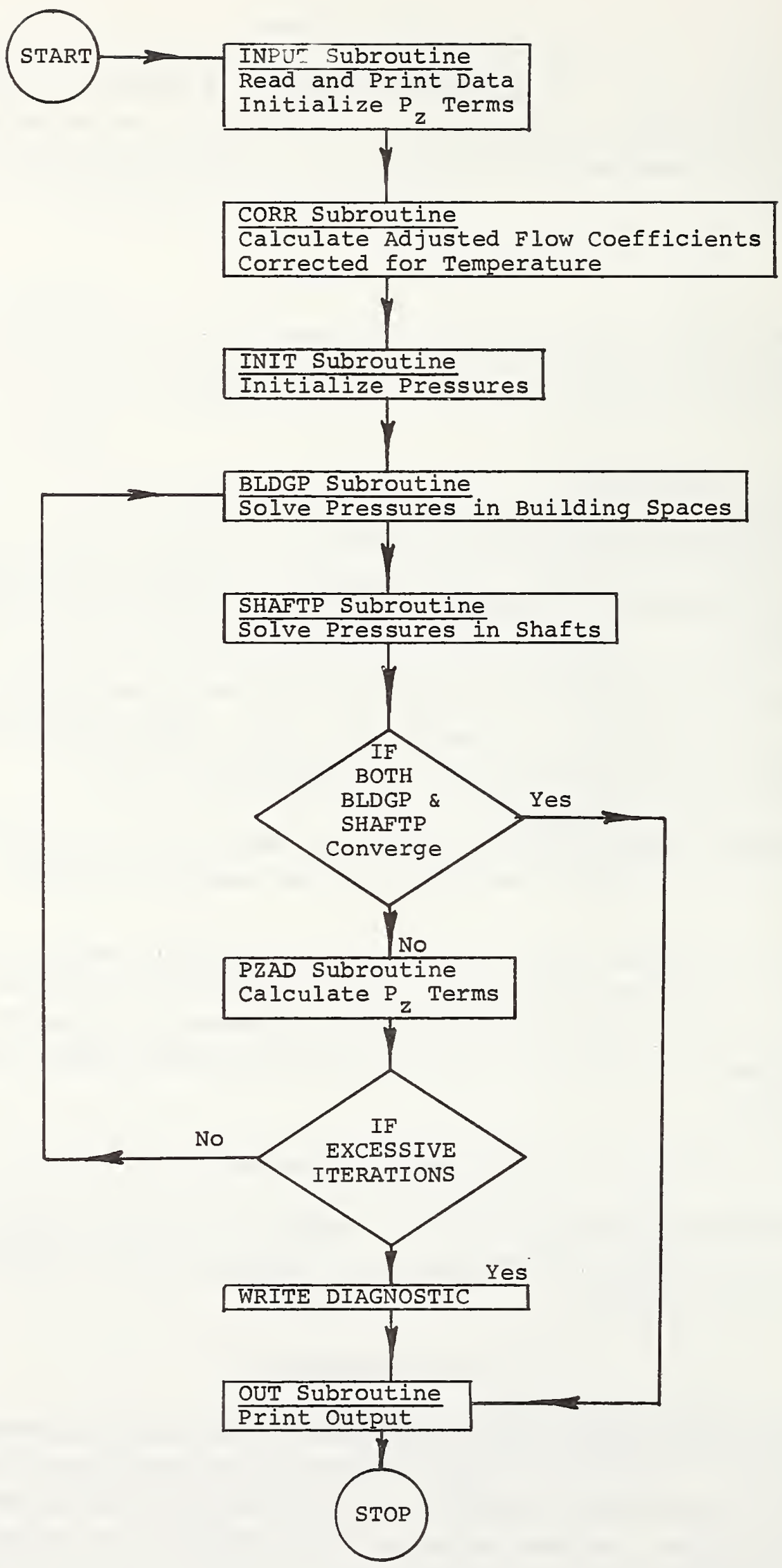

Figure 1. Flow chart for main program 


\subsection{BLDGP Subroutine}

The iterative solution for the building pressures and flows consists of trie three subroutines BLDGP, SHAFTP and PZAD. The subroutine BLDGP operates on the building compartments sequentially. The sum of all the mass flows into compartment $i$ is calculated. If the absolute value of this sum is less than a convergence limit then eq. (3.3) is considered satisfied and the computer proceeds to the next compartment or returns to the main program. However, if the absolute value of the sum is greater than the convergence limit, then an improved estimate of the pressure at compartment $i$ is obtained by the regula falsi method [14]. When none of the pressures need to be modified this routine passes a convergence signal to the main program.

\subsection{SHAFTP Subroutine}

The structure of this routine is very similar to that of BLDGP except that it operates on shafts sequentially. The sum of all the mass flows into shaft $i$ is calculated. If the absolute value of this sum is less than the convergence limit then eq. (3.4) is also considered satisfied and the computer proceeds to the next shaft or returns to the main program. However, if the absolute value of the sum is greater than the convergence limit, then improved estimates of the shaft pressure are calculated. This is done by changing the pressures at the bottom of the shaft and then recalculating the shaft pressure by eq. (3.5). Again the regula falsi method is used, and if none of the shaft pressures require modification a convergence signal is passed to the main program. It can be seen from figure 1 that if convergence is achieved in both BLDGP and SHAFTP, then the subroutine OUT will print the solution. Otherwise, the hydrostatic pressure differences are adjusted in the subroutine PZAD.

\subsection{PZAD Subroutine}

This routine calculates hydrostatic pressure differences by eq. (3.6) using the most recent pressure estimates.

\subsection{OUT Subroutine}

This routine outputs mass flows and pressures for the flow network as well as the differential pressures across each shaft. If the data input was in engineering units then appropriate variables are converted to the engineering system before output.

\section{FUTURE DIRECTION}

It is planned to use this computer program in a project at NBS to study the feasibility of protected elevators as a means of fire escape for handicapped individuals. Consideration is being given to further development of the program for use as a design tool. Also, a program may be developed for microcomputers which can be used interactively. 


\section{REFERENCES}

[1] Sander, D. M., FORTRAN IV Program to Calculate Air Infiltration in Buildings, National Research Council Canada, DBR Computer Program No. 37, May 1974.

[2] Sander, D. M. and Tamura, G. T., FORTRAN IV Program to Simulate Air Movement in Multi-Story Buildings, National Research Council Canada, DBR Computer Program No. 35, March 1973.

[3] Yoshida, H., Shaw, C. Y. and Tamura, G. T., A FORTRAN IV Program to Calculate Smoke Concentrations in a Multi-Story Building, National Research Council Canada, DBR Computer Program No. 45, June 1979.

[4] Butcher, E. G., Fardell, P. J. and Jackman, P. J., Prediction of the Behaviour of Smoke in a Building using a Computer, symposium on Movement of Smoke on Escape Routes in Buildings, Watford College of Technology, Watford, Herts, England, pp. 70-75, 1969.

[5] Barrett, R. E. and Locklin, D. W., A Computer Technique for Predicting Smoke Movement in Tall Buildings, Symposium on Movement of Smoke on Escape Routes in Buildings, Watford College of Technology, Watford, Herts, England, pp. 78-87, 1969.

[6] Evers, E. and Waterhouse, A., A Computer Model for Analyzing Smoke Movement in Buildings, BRE Fire Research Station, Borehamwood, Hertsfordshire, England, November 1978 .

[7] Wakamatsu, T., Calculation Methods for Predicting Smoke Movement in Building Fires and Designing Smoke Control Systems, Fire Standards and Safety, ASTM STP 614, A. F. Robertson, Ed., American Society for Testing and Materials, pp. 168-193, 1977.

[8] Klote, J. H., A Computer Program for Analysis of Pressurized Stairwells and Pressurized Elevator Shafts, Nat. Bur. Stand. (U.S.), NBSIR 80-2157, January 1981.

[9] Klote, J. H., Smoke Control by Stairwell Pressurization, Engineering Applications of Fire Technology, SFPE and Nat. Bur. Stand., April 1980.

[10] Sachs, P., Wind Forces in Engineering, Pergamon Press, New York, 1972.

[11] Houghton, E. L. and Carruther, N. B., Wind Forces on Buildings and Structures, John Wiley \& Sons, New York, 1976.

[12] Simiu, E. and Scanlan, R. H., Wind Effects on Structures: An Introduction to Wind Engineering, John Wiley \& Sons, New York, 1978.

[13] MacDonald, A. J., Wind Loading on Buildings, John Wiley \& Sons, New York, 1975.

[14] Carnahan, B., Luther, H. A. and Wilkes, J. O., Applied Numerical Methods, John Wiley \& Sons, Inc., New York, 1969. 
Data input consists of the following elements:

1. Initial data

2. Building heights

3. Temperature profiles

4. Outside pressure profiles

5. Building data

6. Shaft data

Each of these input elements is described in detail in the following sections. Elements 1 through 6 are always required. In the following sections the input required for each of the six data elements is described in detail. Each block or group of blocks below represent an input card. Unless otherwise stated these cards are unformatted; that is, the numbers do not have to be placed in specific columns and integers can be written with or without decimal points. However, separate pieces of numerical data must be separated by one or more spaces. Examples of input data are provided in Appendix B.

1. Initial data

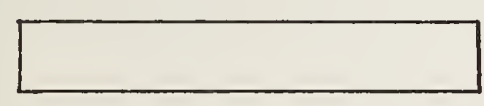

project title. (col. 1-72)
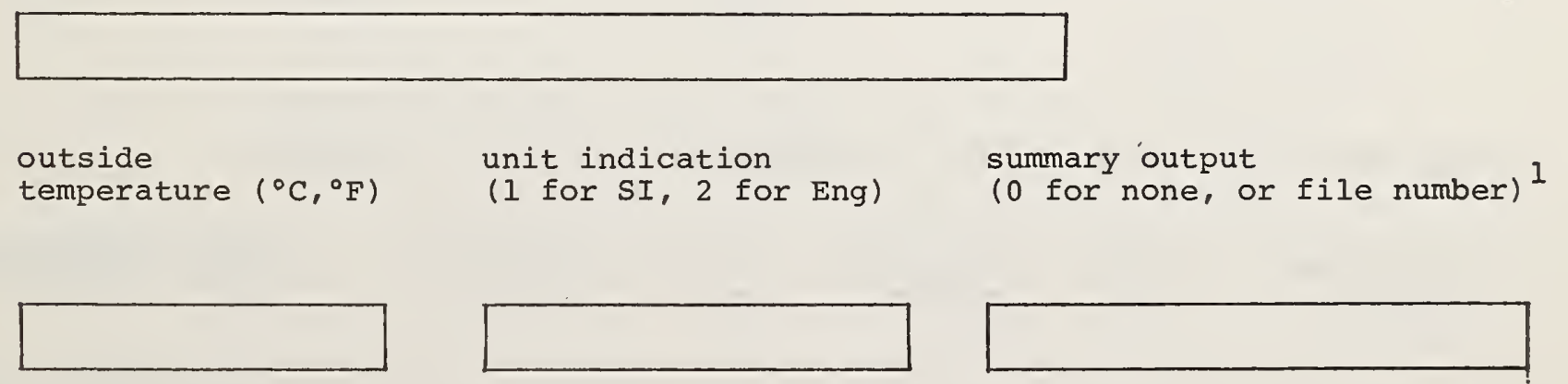

\footnotetext{
$I_{\text {The }}$ user must assign this file before program execution.
} 
2. Building heights

$\mathrm{N}_{\mathrm{h}^{\prime}}$ no. of building

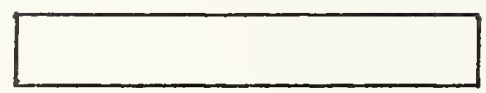

input parameter

(either 0 or 1 )

If input parameter $=0$, then heights for each building level are to be individually entered as follows:

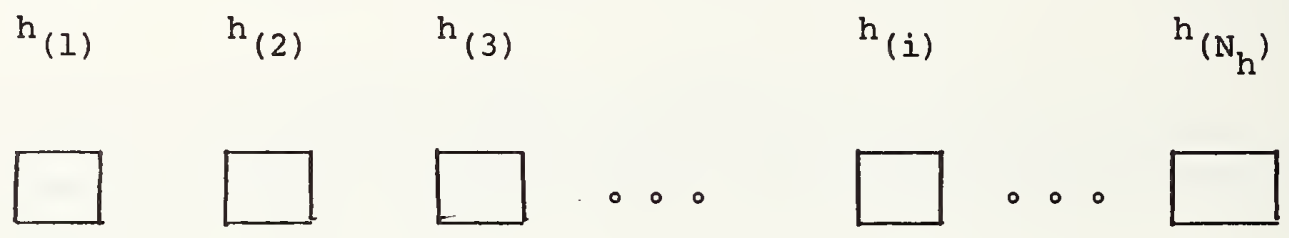

where $h(i)$ is the height of the center of level $i$ above the ground ( $m$, $f t$ ).

If input parameter $=1$, then the following card must be entered.
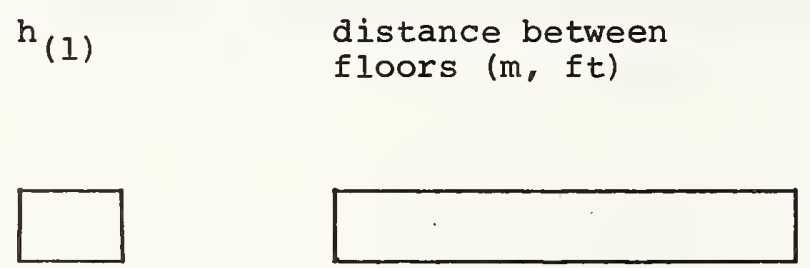

3. Temperature profiles

no. of temperature profiles

For each temperature profile the following data must be supplied.

no. of temp. level temperature level temperature level temperature points no. $\left({ }^{\circ} \mathrm{C},{ }^{\circ} \mathrm{F}\right)$ no. $\left({ }^{\circ} \mathrm{C},{ }^{\circ} \mathrm{F}\right)$ no. $\left({ }^{\circ} \mathrm{C},{ }^{\circ} \mathrm{F}\right)$
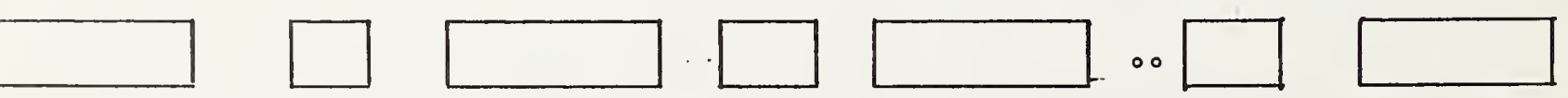
4. Outside pressure profiles
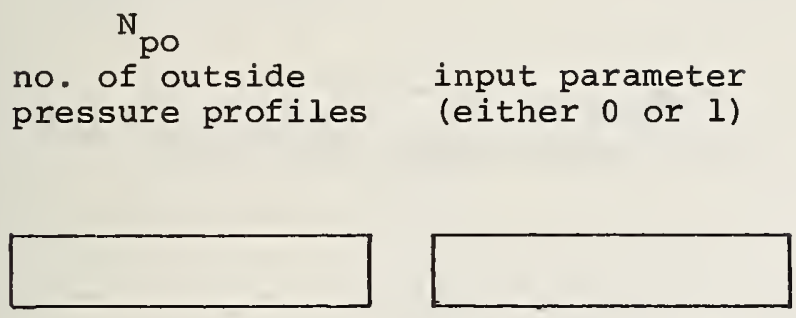

If the input parameter $=0$, each outside pressure profile is entered as follows:
$\mathrm{P} \circ(1)$
$P_{\circ}(2)$
$P_{\circ}(3)$
$P_{\circ}(i)$
$P_{\circ} \circ\left(N_{h}\right)$
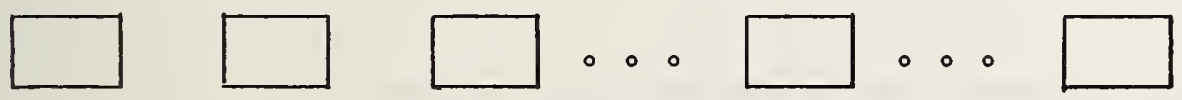

where $P_{O}(i)$ is the outside pressure at the center of level $i$.

If the input parameter $=1$, the outside pressures are calculated and the following data are required.
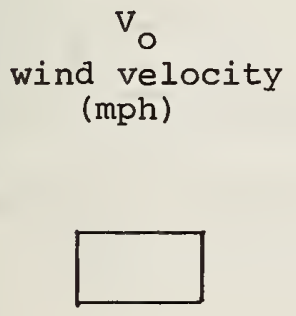

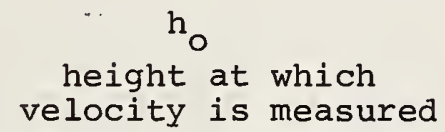

velocity is measured

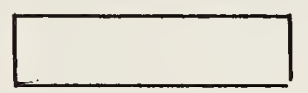

$\mathrm{n}$

wind

exponent

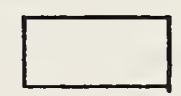

pressure coefficients for each pressure profile

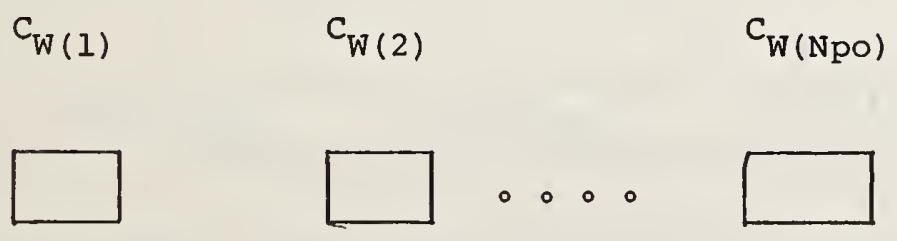

5. Building data

$\mathrm{N}_{\mathrm{f}}$

no. of levels

(or floors) 
All of the following data in this input element are supplied for each level, or consecutive groups of similar levels.

$I_{1}$

Starting floor
$I_{2}$

Ending floor
$\mathrm{N}_{\text {com }}$

No. of compartments per floor
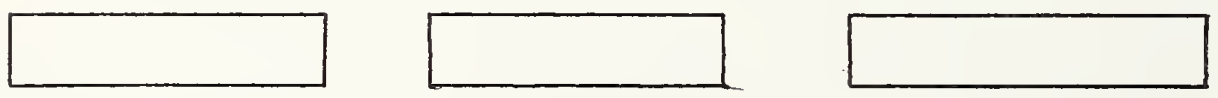

(Floor data is entered in ascending order of levels or floors. When data is for only one level then $I_{1}=I_{2}$, and the same number is supplied for both.)

For each compartment on a level the following datä are supplied:

$\mathrm{N}_{\mathrm{CS}} \mathrm{N}_{\mathrm{CA}} \mathrm{N}_{\mathrm{CO}}$

No. of connections to other compartments on the same level to compartments on the level above
No. of connections to the outside
$F_{\mathrm{f}}$ Net flow $^{2}$ $(1 / s, c f m)$ Temperature profile number
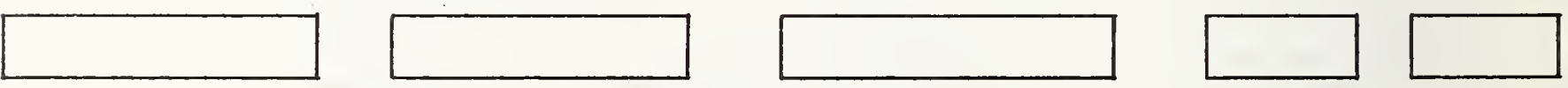

For each connection between this compartment and another on the same floor the following data are required.

Other compartment number on the same level

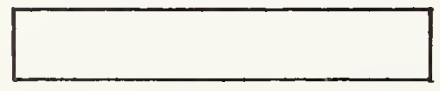

C flow coefficient

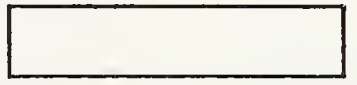

A flow area $\left(\mathrm{m}^{2}, \mathrm{ft} \mathrm{t}^{2}\right)$

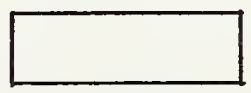

For each connection between this compartment and one on the level above the following data are required.

${ }^{2} \mathrm{All}$ net flows are at standard conditions of $21^{\circ} \mathrm{C}\left(70^{\circ} \mathrm{F}\right)$ and one atmosphere. 
Other compartment number on floor above

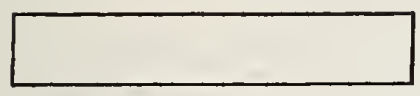

C

flow coefficient flow area

For each connection to the outside the following data are required.

outside pressure profile number
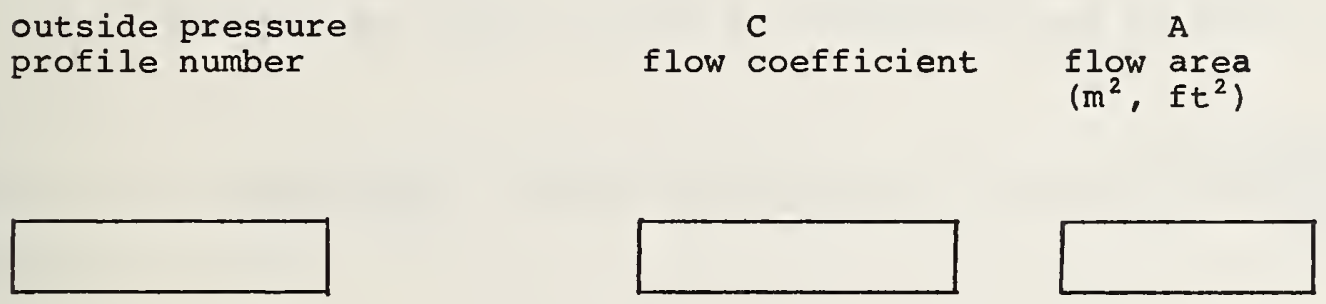

6. Shaft data

no. of shafts

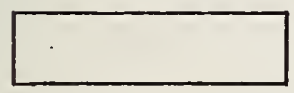

All of the following data in this input element are required for each shaft. shaft title (col 1-20)
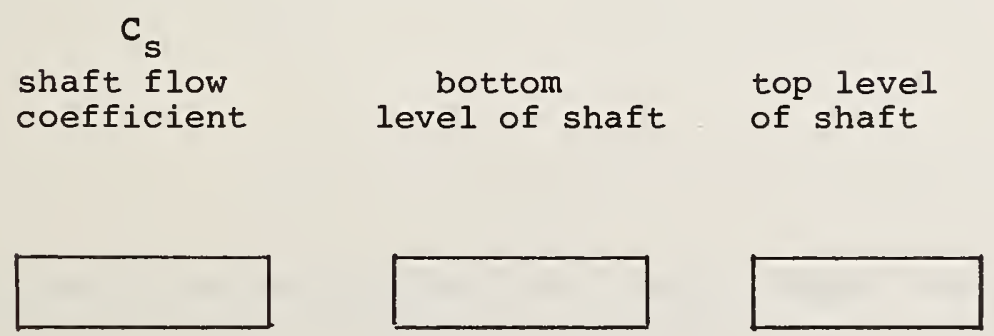

temperature profile number

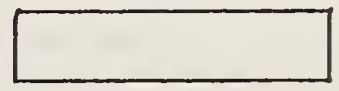

Enter the following typical data which applies to each level of the shaft.

Exceptions can be entered later. 
no. of connections

between typical

level of shaft and outside

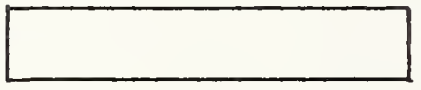

$F_{f}$

net flow into

typical level

of shaft

$(1 / s$, cfm $)$

The connection data to the building for a typical level are required.

compartment no.

to which shaft is connected

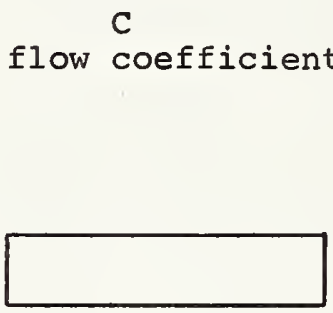

A

flow area

$\left(m^{2}, f t^{2}\right)$

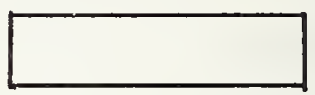

For each connection to the outside, the connection data for a typical floor are required.

$$
\begin{aligned}
& \text { outside pressure } \\
& \text { profile }
\end{aligned}
$$

A

flow area

$\left(\mathrm{m}^{2}, \mathrm{ft} \mathrm{t}^{2}\right)$

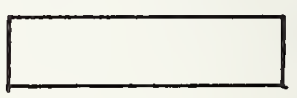

The number of exceptions to the typical data is required.

no. of exceptions

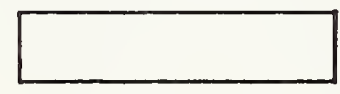

All of the following data in this input element are required for each exception.

exception type

$(1,2$ or 3$)$ level of shaft
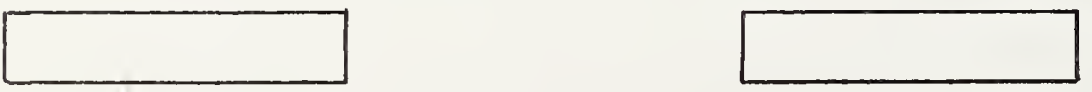
The next card depends on the exception type. For exception type $=$ ? to the net flow into the floor of the shaft is defined.

$$
\begin{aligned}
& F_{f} \\
& \text { net flow } \\
& (1 / s, \text { cfm })
\end{aligned}
$$

For exception type $=2$, an exception to an outside connection for this shaft is defined.

$$
\begin{aligned}
& \text { outside pressure } \\
& \text { profile number }
\end{aligned}
$$

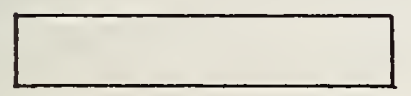

flow $\stackrel{C}{\text { coefficient }}$

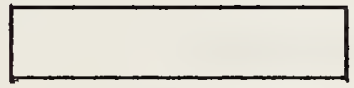

A

flow area

$\left(\mathrm{m}^{2}, \mathrm{ft} \mathrm{t}^{2}\right)$

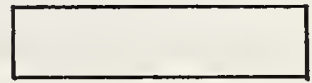

For exception type $=3$, an exception to the connection between the shaft and the building is defined.

compartment no.

to which shaft

is connected
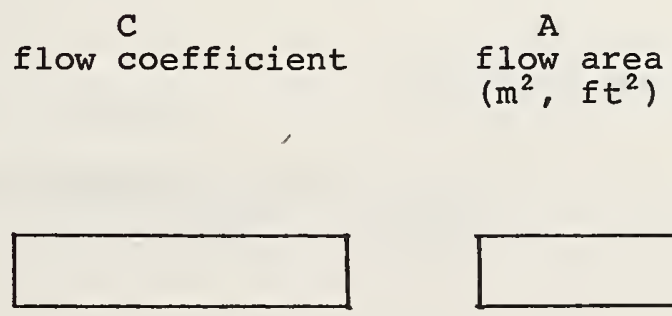

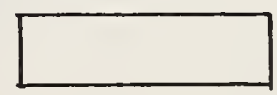


1. Example I

A ten story building with a pressurized stairwell and no vertical leakage within the building is heated to $70^{\circ} \mathrm{F}$ when the outside temperature is $-20^{\circ} \mathrm{F}$. The stairwell temperature is $60^{\circ} \mathrm{F}$ at the tenth floor and $50^{\circ} \mathrm{F}$ at the bottom floor. The stairwell is pressurized by a net $550 \mathrm{cfm}^{\mathrm{I}}$ per floor. The wind is $30 \mathrm{mph}$ at a height of $30 \mathrm{ft}$ and the wind exponent is 0.14 . This building has connections to the outside in two directions. The wind pressure coefficients are 0.7 for the windward wall and -0.7 for the leaward wall. The flow areas are the same vertically and are listed in Table Bl. The flow coefficient is taken to be 0.65 for all connections.

Table Bl. Flow areas for example 1

\begin{tabular}{lc} 
Connection location & Area (ft $\left.{ }^{2}\right)$ \\
\hline $\begin{array}{l}\text { Between stairwell \& building } \\
\begin{array}{l}\text { Between building \& outside into } \\
\text { the wind }\end{array}\end{array}$ & 0.42 \\
$\begin{array}{l}\text { Between building \& outside away } \\
\text { from the wind }\end{array}$ & 0.75 \\
\hline
\end{tabular}

1.1 Data for Computer Input

\begin{tabular}{|c|c|c|c|c|c|c|c|}
\hline $\begin{array}{l}\text { initial } \\
\text { data }\end{array}$ & $\left\{\begin{array}{l}\text { TEN } \\
-20\end{array}\right.$ & STORY & $\begin{array}{l}\text { BUILDI } \\
20\end{array}$ & NG & WITHOUT & VERTICAL & LEAKAGE \\
\hline $\begin{array}{l}\text { building } \\
\text { heights }\end{array}$ & $\left\{\begin{array}{r}10 \\
5\end{array}\right.$ & & $\begin{array}{r}1 \\
10\end{array}$ & & & & \\
\hline $\begin{array}{l}\text { temperature } \\
\text { profizes }\end{array}$ & $\left\{\begin{array}{l}2 \\
1 \\
2\end{array}\right.$ & & $\begin{array}{l}1 \\
1\end{array}$ & $\begin{array}{l}70 \\
50\end{array}$ & 10 & 0 & 60 \\
\hline $\begin{array}{l}\text { outside } \\
\text { pressure } \\
\text { profiles }\end{array}$ & $\left\{\begin{array}{r}2 \\
30 \\
0.7\end{array}\right.$ & & $\begin{array}{r}1 \\
30 \\
-0.7\end{array}$ & .15 & & & \\
\hline
\end{tabular}

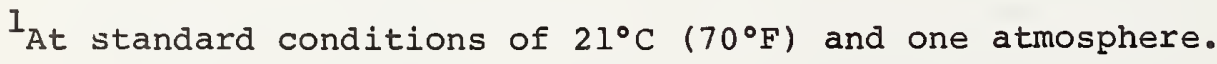




\begin{tabular}{|c|c|c|c|c|}
\hline $\begin{array}{l}\text { building } \\
\text { data }\end{array}$ & $\begin{array}{r}10 \\
1 \\
0 \\
1 \\
2\end{array}$ & $\begin{array}{r}10 \\
0 \\
.65 \\
.65\end{array}$ & $\begin{array}{r}1 \\
2 \\
0.75 \\
0.75\end{array}$ & 0 \\
\hline $\begin{array}{l}\text { shaft } \\
\text { data }\end{array}$ & $\begin{array}{r}1 \\
\text { STA } \\
80000 \\
0 \\
1 \\
0\end{array}$ & $\begin{array}{r}1 \\
550 \\
.65\end{array}$ & $\begin{array}{r}10 \\
.42\end{array}$ & 2 \\
\hline
\end{tabular}

\section{Example 2}

This is a 10 story building which is $70^{\circ} \mathrm{F}$ inside. Outside the air temperature is $-5^{\circ} \mathrm{F}$ and there is no wind. This building has a stairwell and an elevator. The flow areas which are generally the same vertically are listed in table B2 and the flow exponents are taken to be 0.5 . The stairwell is pressurized by a net 550 cfm per floor. The elevator shaft has a $4 \mathrm{ft}^{2}$ vent to the outside at the top. On floors 2 through 10 the elevator lobby separated from the building by doors that automatically close in the event of a fire. The flow coefficient is taken as 0.65 in all connections.

Table B2. Flow areas for example 2

Connection location

Between stairwell \& building

Between building \& outside

Between elevator \& elevator lobby

Between elevator lobby \& building
Area $\left(f t^{2}\right)$
0.42
1.5
0.65
0.55

2.1 Data for Computer Input

\begin{tabular}{|c|c|c|c|}
\hline $\begin{array}{l}\text { initial } \\
\text { data }\end{array}$ & $\left\{\begin{array}{l}\text { TEN } \\
-5\end{array}\right.$ & $\begin{array}{c}\text { STORY } \\
2\end{array}$ & $\begin{array}{c}\text { BUILDING WITH } \\
0\end{array}$ \\
\hline $\begin{array}{l}\text { building } \\
\text { heights }\end{array}$ & $\left\{\begin{array}{r}10 \\
5\end{array}\right.$ & $\begin{array}{r}1 \\
10\end{array}$ & \\
\hline $\begin{array}{l}\text { temperature } \\
\text { profize }\end{array}$ & $\left\{\begin{array}{l}1 \\
1\end{array}\right.$ & 1 & 70 \\
\hline $\begin{array}{l}\text { outside } \\
\text { pressure } \\
\text { data }\end{array}$ & $\left\{\begin{array}{l}1 \\
0 \\
1\end{array}\right.$ & $\begin{array}{l}1 \\
1\end{array}$ & 1 \\
\hline
\end{tabular}


buizding

data

\begin{tabular}{|c|c|c|c|c|}
\hline $\begin{array}{l}\text { lst } \\
\text { floor }\end{array}$ & $\begin{array}{l}1 \\
0 \\
1\end{array}$ & $\begin{array}{r}1 \\
0 \\
0.65\end{array}$ & $\begin{array}{c}1 \\
1 \\
0.75\end{array}$ & 0 \\
\hline $\begin{array}{l}\text { 2nd } \\
\text { through } \\
\text { loth floors }\end{array}$ & $\begin{array}{l}2 \\
1 \\
2 \\
1 \\
0\end{array}$ & $\begin{array}{r}10 \\
0 \\
0.65 \\
0.65 \\
0\end{array}$ & $\begin{array}{c}2 \\
1 \\
0.55 \\
0.75 \\
0\end{array}$ & 0 \\
\hline
\end{tabular}

shaft

data

$$
\text { shaft } 2 \quad\left\{\begin{array}{rrrr}
\text { STAIRWELL } & \\
80000 & 1 & 10 & 1 \\
0 & 550 & & \\
1 & .65 & .42 & \\
0 & & & \\
\text { shaft } 2 & \multicolumn{5}{|c}{\text { ELEVATOR }} & & \\
2.7 \mathrm{E} 6 & 1 & 10 & 1 \\
0 & 0 & & \\
2 & .65 & .65 & \\
2 & & & \\
2 & 10 & & \\
1 & .65 & 4.0 \\
3 & 1 & & \\
1 & .65 & .65 &
\end{array}\right.
$$

2.2 Example 2 Output

The output for example 2 case 1 (the data above not including modifications for Cases 2 and 3 ) is given in appendix $C$. 
APPENDIX C. EXAMPLE OUTPUT 

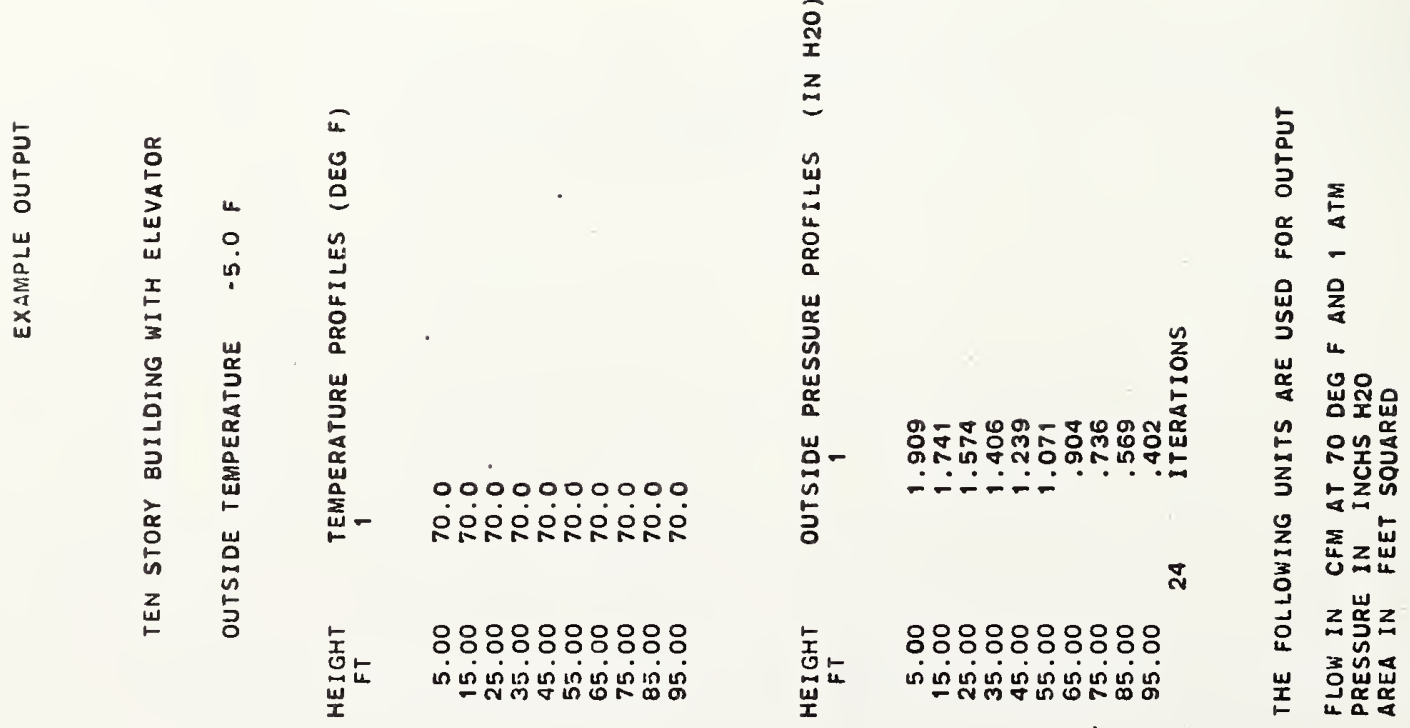


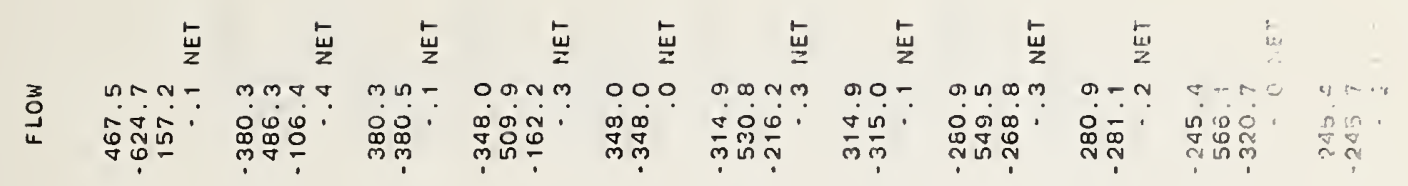

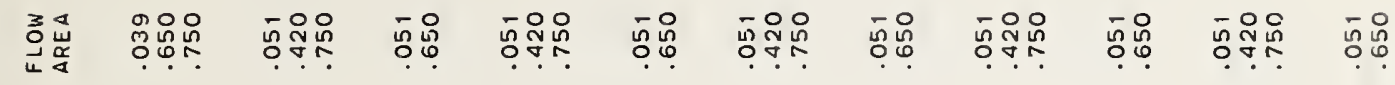

s.

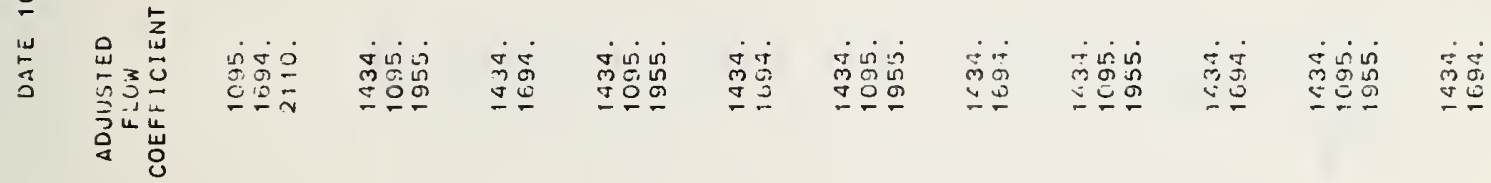

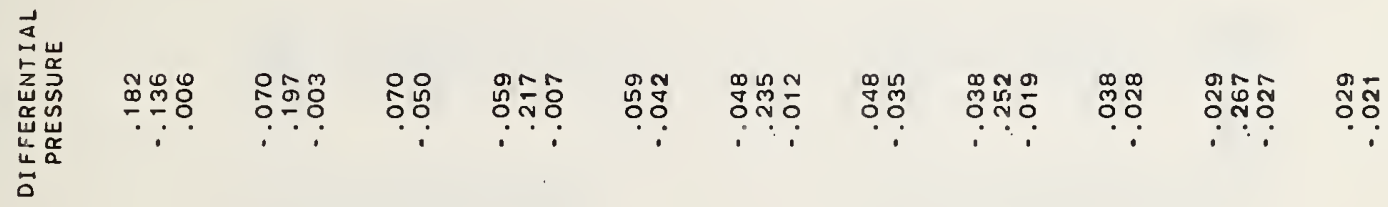

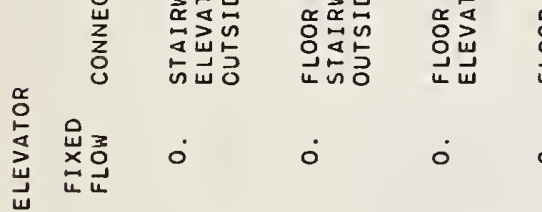

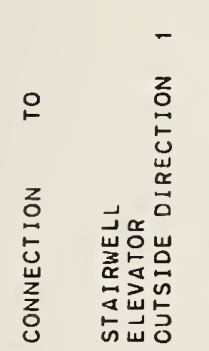

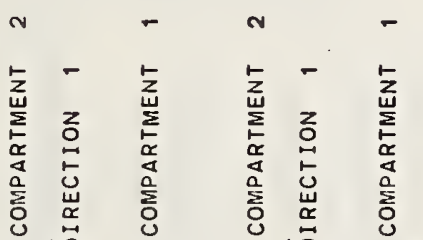

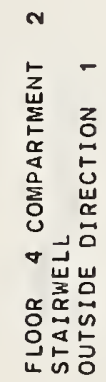

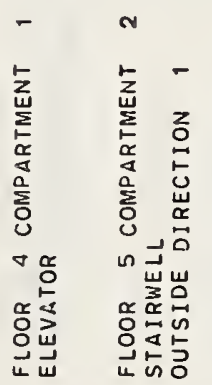

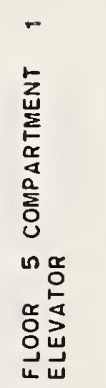

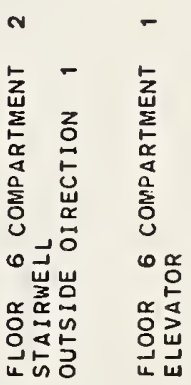

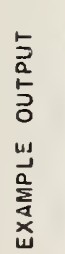

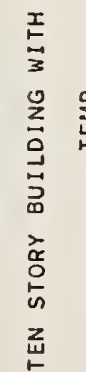

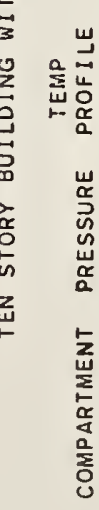

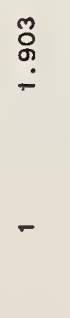

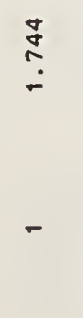

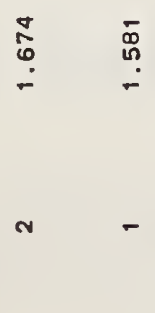

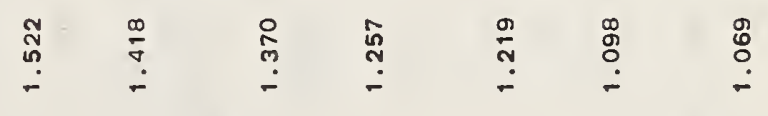

繁

o

ง

(3) 


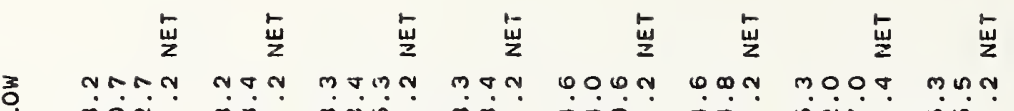

₹

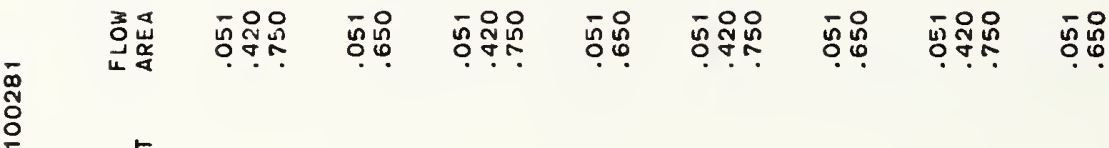

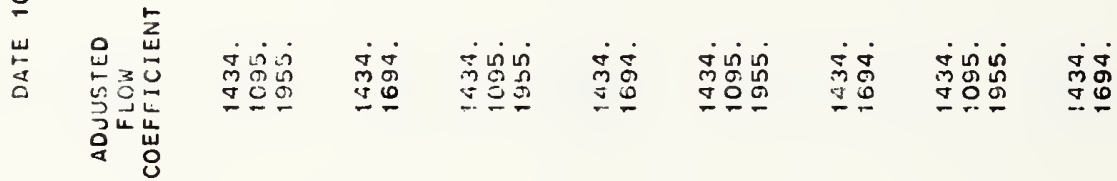

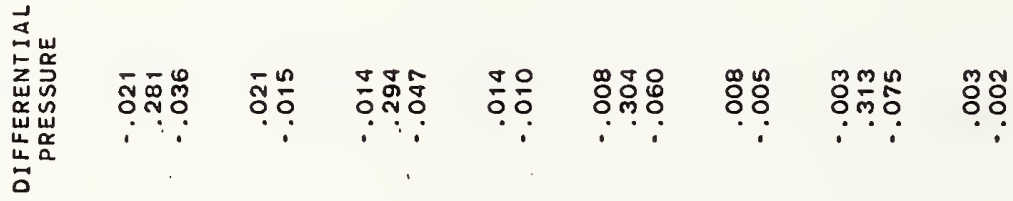

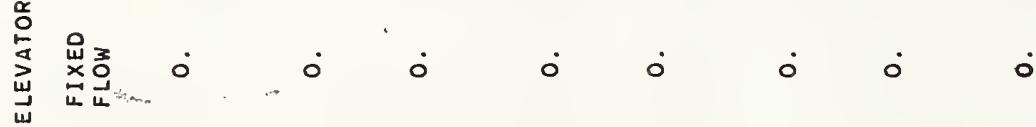

点

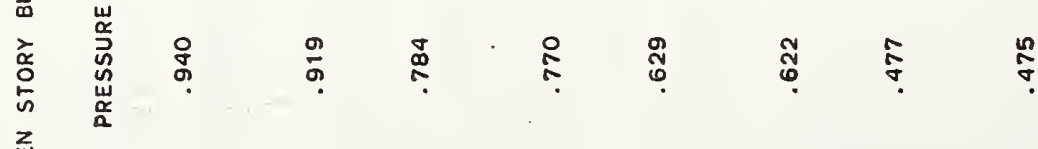

z

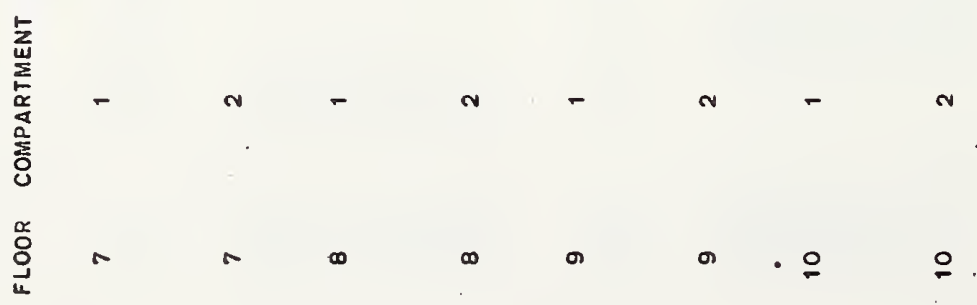




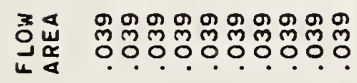

궈
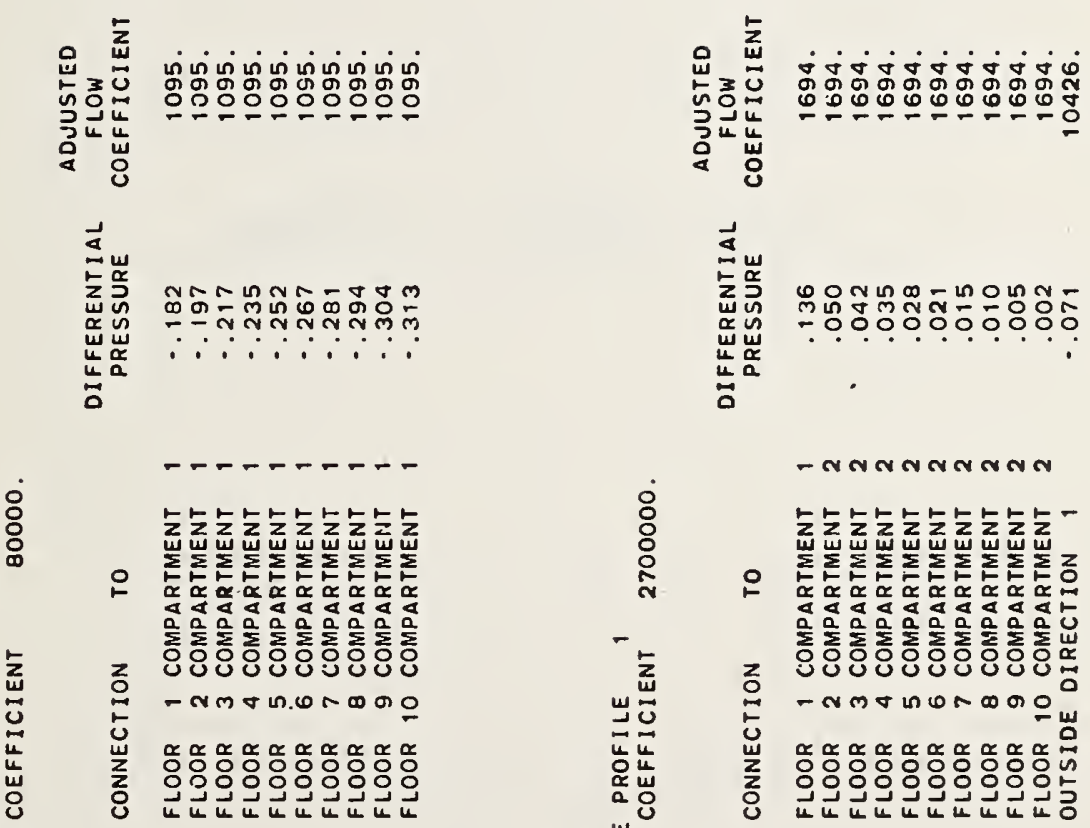

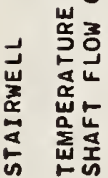

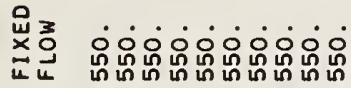

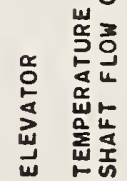

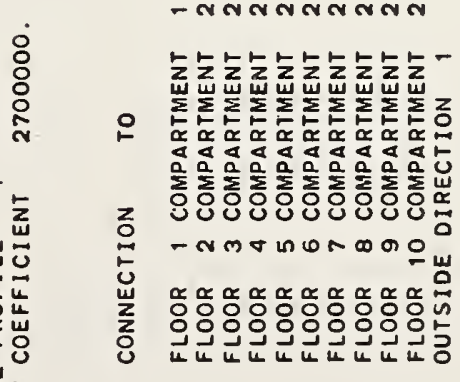

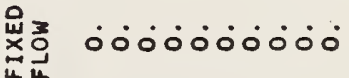
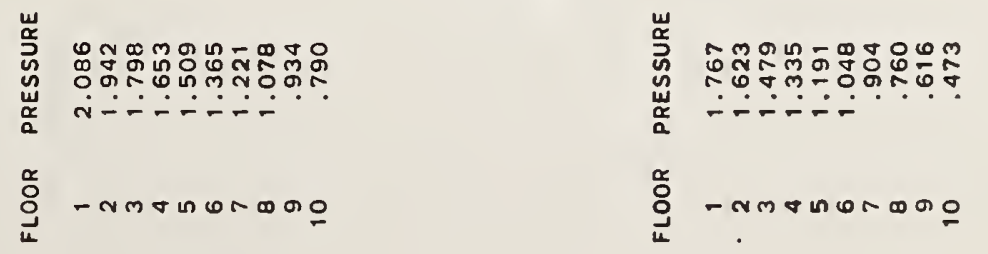
APPENDIX D. PROGRAM LISTING 



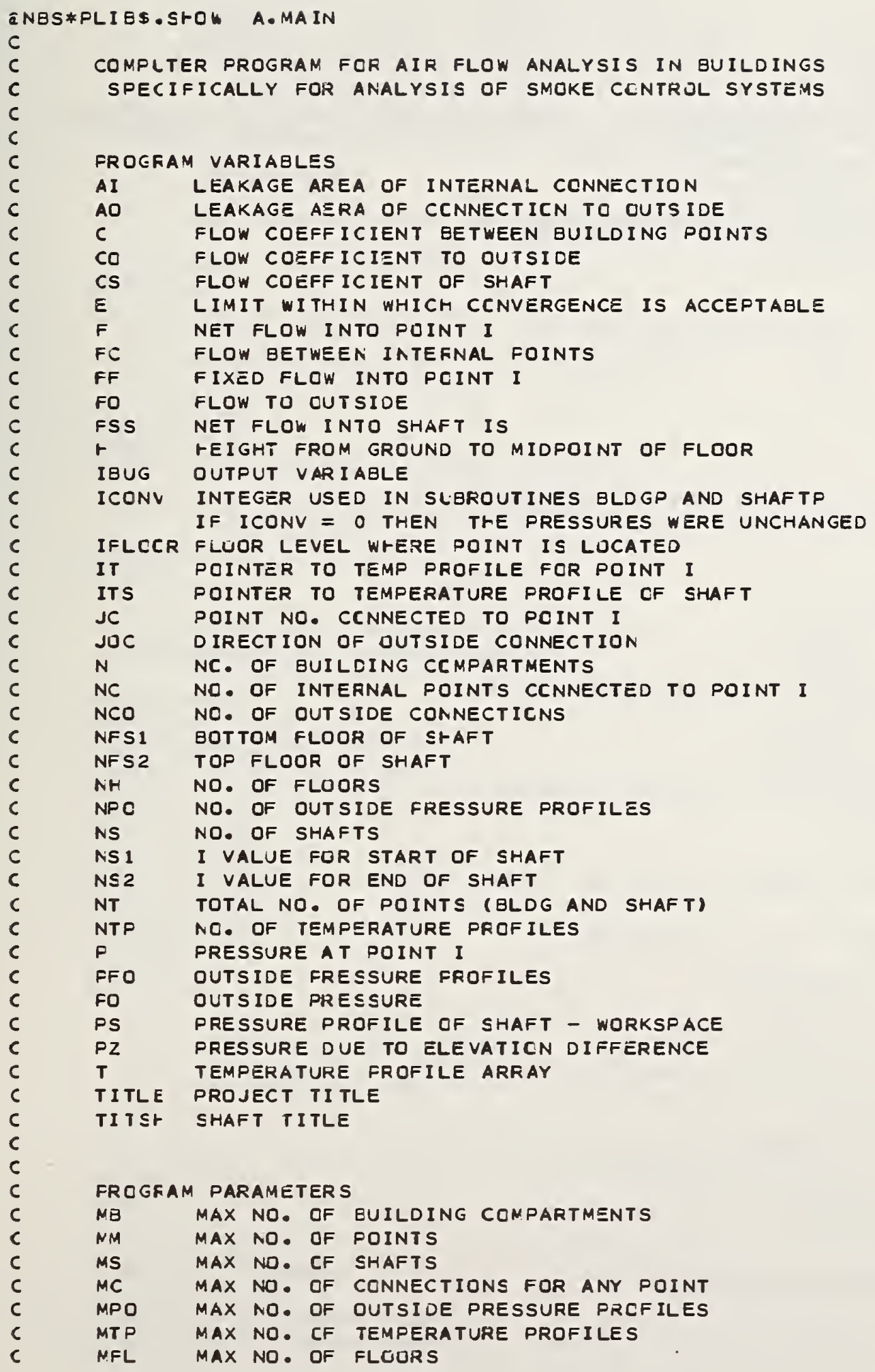


PARAMETER (MM=140, MS $=8, M C=9, M F C=2, M T P=2, M F L=25, M B=50)$

CCMMCN NT, $P(M M), C(M M, M C), N C(M M), J C(M M, M C), I T S(M S)$,

$1 F C(M M, M C), P Z(M M, M C), P O(M M, M P O), C O(M M, M P O), F(M M), P F U(M F L, M P O)$.

$2 F F(N M), F O(M M, M F O), C S(N S), P S(M F L), N S 1$ (MS),NS2 (MS).

3 FSS(MS),N,NS,NPO, ICONV, E, IBUG, AI (MM,MC), AO(MM,MPO), TITSH(MS,5),

$4 \mathrm{NH}, \mathrm{H}(M F L), I F L O O R(M M), T(M T P, M F L), N F S 1(M S), N F S 2(M S), I T(M B), N T P$

5 . NCC $(M M), J O C(M M, M F Q)$. TOUT

DOUELE PRECISION P.PO.PS

COMMCN/RUN/IRUN

CIMEASION 81 ( MM.MC),B2(MM,MFO)

NI TEF $=5000$

c

IRUN $=1$

CALL INPUT TO READ CATA

CALL INPUT

C

$E=0.2$

IC $S=1$

SAVE AI(I,J) IN BI $(I, J)$ AND FIND

MAX VALUE OF $A I(I, J)$

c

$A Z Z=C$

AMAX $=0$

CO $10 \quad I=1$.NT

Cu $8, J=1, M C$

$E I(I, J)=A I(I, J)$

IF $(A I(I, J), G T$. AMAX)AMAX $=A I(I, J)$

e

CONTINLE

DO $9 J=1, M P C$

$E 2(I, J)=A O(I, J)$

$\operatorname{IF}(A C(I, J) \cdot G T \cdot A M A X) A M A X=A O(I, J)$

与

CONTINUE

10 CONTINUE

$c$

c

c

ACJUST FOR LARGE VALUES OF FLOW AREA

IF (ANAX -LT. 0. I) GO TO 25

$A Z Z=1$

$A M=0.2 /(A M A X-0.1)$

$E B=0.1 *(1.0-A M)$

CO $1 \mathrm{E} I=1 . \mathrm{NT}$

CO 1 \& $J=1, M C$

IF (AI I.J) .LT. O.1)GO TO 12

12 CONTINUE

DO $14 \mathrm{~J}=1, \mathrm{MPO}$

$\operatorname{IF}(A \subset(I, J) \cdot L T \cdot 0.1) G O$ TO 14

$A O(I, J)=A M+A O(I, J)+B B$

14 CONTINUE

15 CONTINUE

c

C

c

TENPERATURE CORRECTICN

CALL CCRR 
MAIN PROGFAM

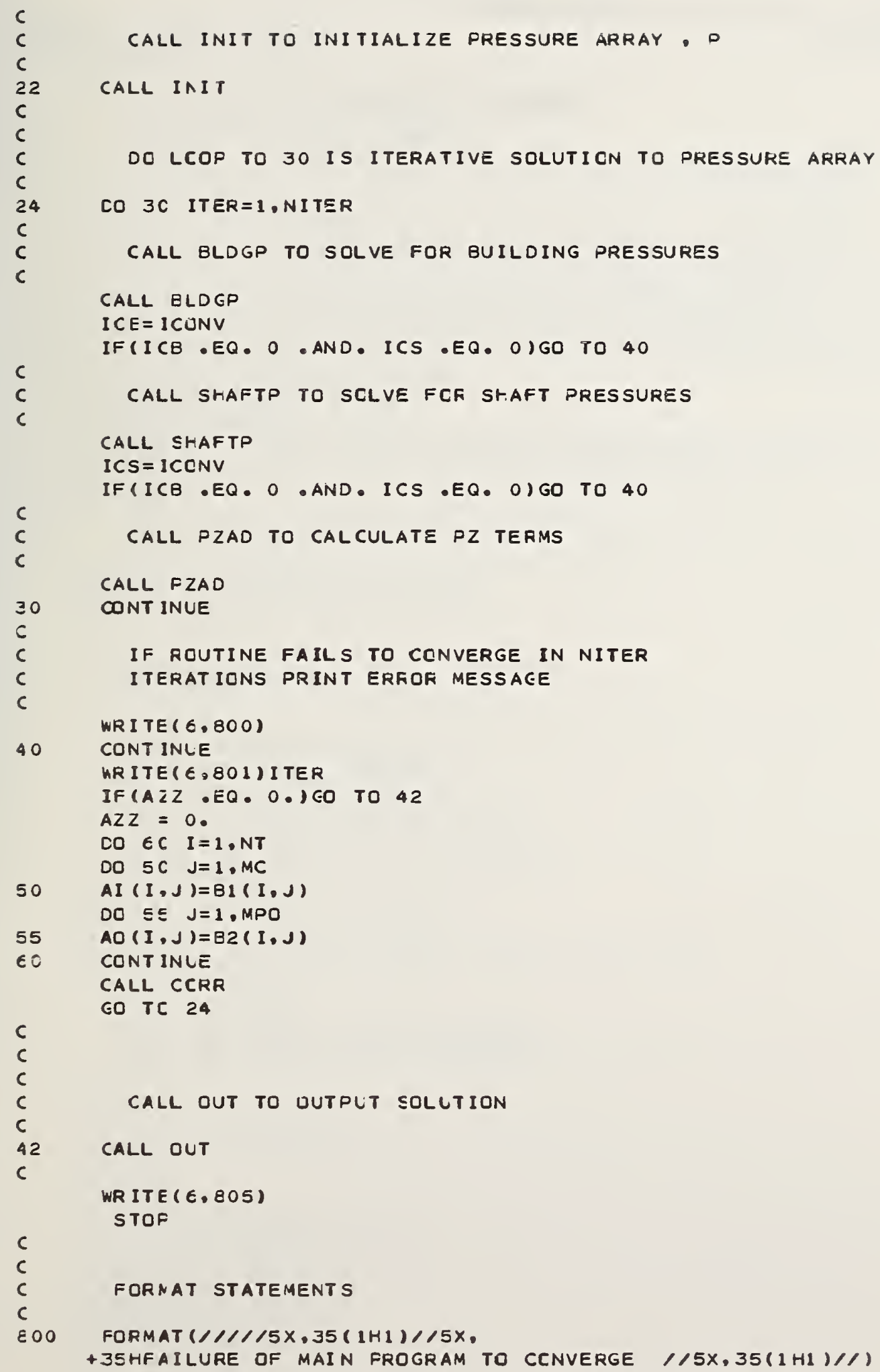

CALL BLDGP TO SOLVE FOR BUILDING PRESSURES

CALL BLDGP 
MAIN PFOGRAM

801

FOFMAT

10X, I5, 5X, 11 HITERATICNS

FORMAT $(1+1)$

END

âDG,P

SUBROUTINE INPUT •L, 1 


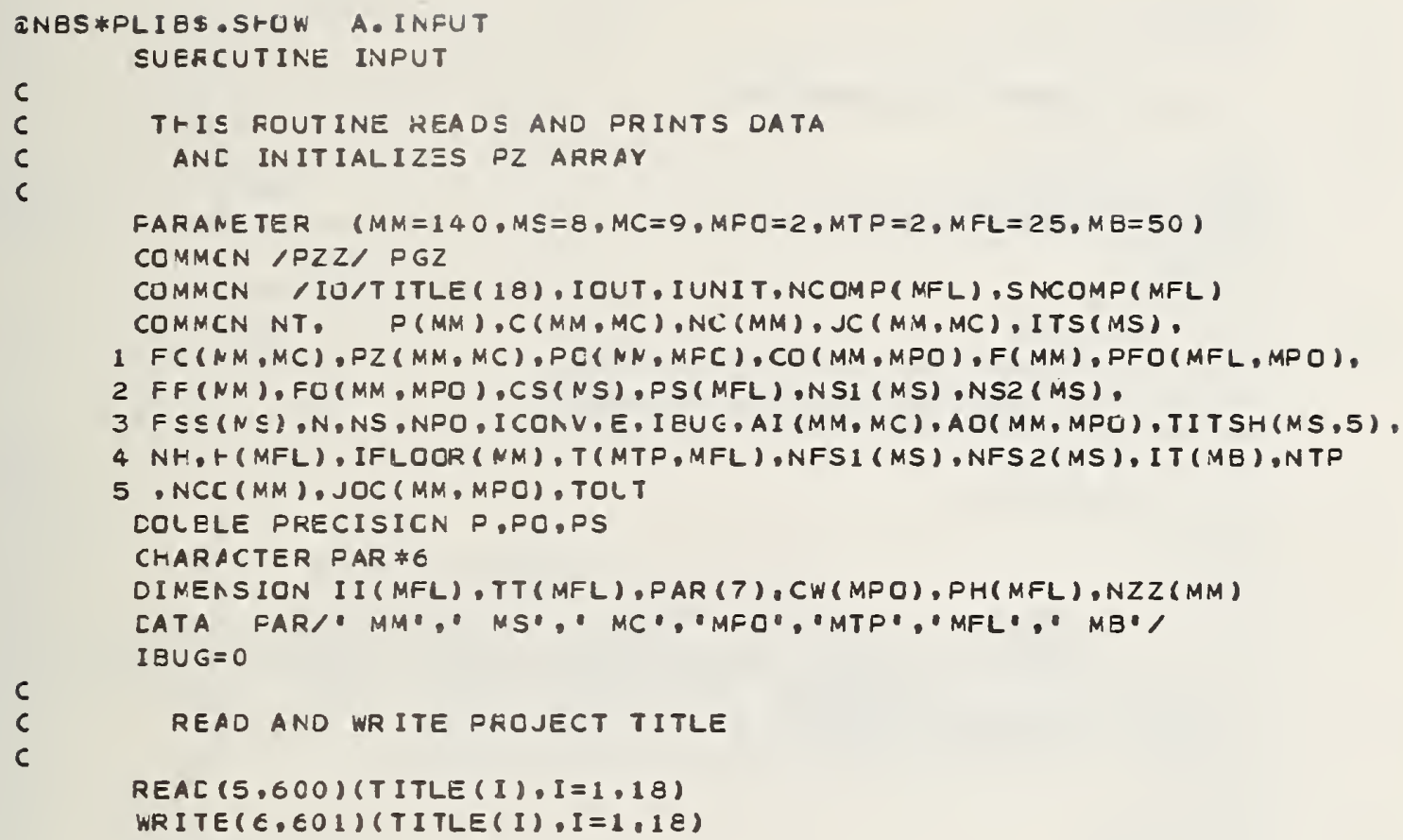

REAC (5,700) TOUT, I UNIT, I OUT WR ITE $(\epsilon, 411)$ TOUT, IUNIT, I CUT 


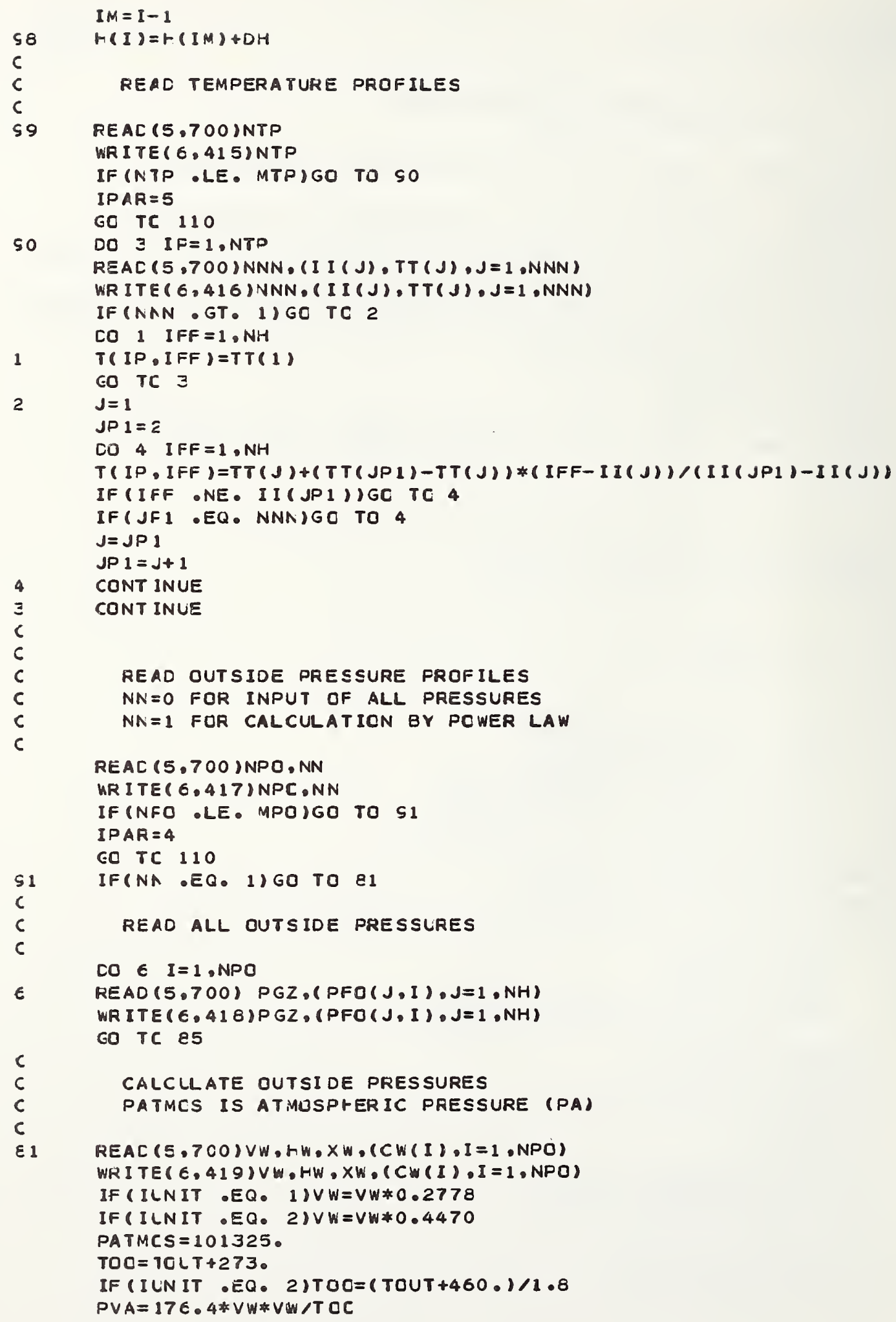

$c$

c

READ ALL OUTSIDE PRESSURES 
$Z=-0.0 \equiv 417 / T 00$

IF (ILNIT $E Q .2) Z=0.3048 * Z$

$C W M=C W(1)$

IF (NFO .EQ. 1)GO TO 212

$O O 211 I=1$.NPO

$\operatorname{IF}(C W(I) \cdot L T \cdot C W M) C W M=C W(I)$

211

CONT INUE

212

$P G Z=F A T M C S * E X P(H(N H) * Z)+C W M * P \vee A *((H(N H) / H W) * *(2 \bullet * X W))-100$.

CO $210 \quad I=1$. NH

PH $(I)=P A T M O S * E X P(H(I) * Z)$

210

CONTINLE

DO $8 \varepsilon I=1$. NPD

CO $E \bar{E} J=1$. NH

PFO $(J, I)=P H(J)+C W(I) * P \vee A *((H(J) / H W) *(2 \cdot * X W))-P G Z$

$\varepsilon 2$

CUNT INUE

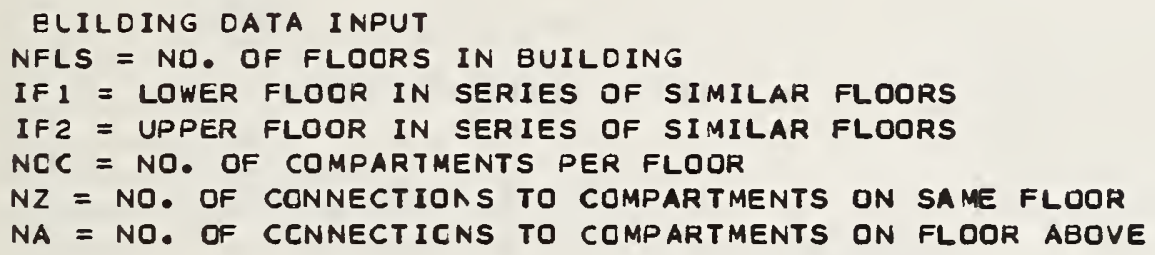

111 IF (NNO.LE. MPO)GO TO 112 IPAR $=4$ 


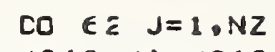

INFUT CONNECTIUNS TO CCMPARTMENTS UN FLOOR ABOVE

\section{$N P=N Z+1$}

$\operatorname{REAC}(5,700)(J C(I, J), C(I, J), A I(I, J), J=N P, N N)$

UR ITE $(E .404)$

WR ITE $(6,403)(J C(I, J), C(I, J), A I(I, J), J=N P, N N)$

DC EE JI=NP,NN

E6 $\operatorname{JC}(I, J)=J C(I, J)+\operatorname{NCCMP}\left(I F_{1}\right)+\operatorname{SNCOMP}\left(I F_{1}\right)$

$\varepsilon \quad N C C(I)=N N O$

IF (NNO EQ. O)GO TO 10

$c$

INFUT CONNECTION TO OLTSIDE

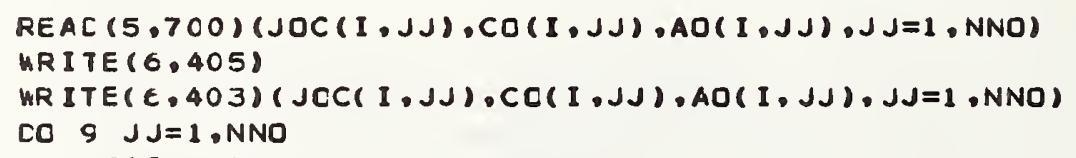

ASICN CATA FOR FLOORS SIMILAR TO FLOOR IFI

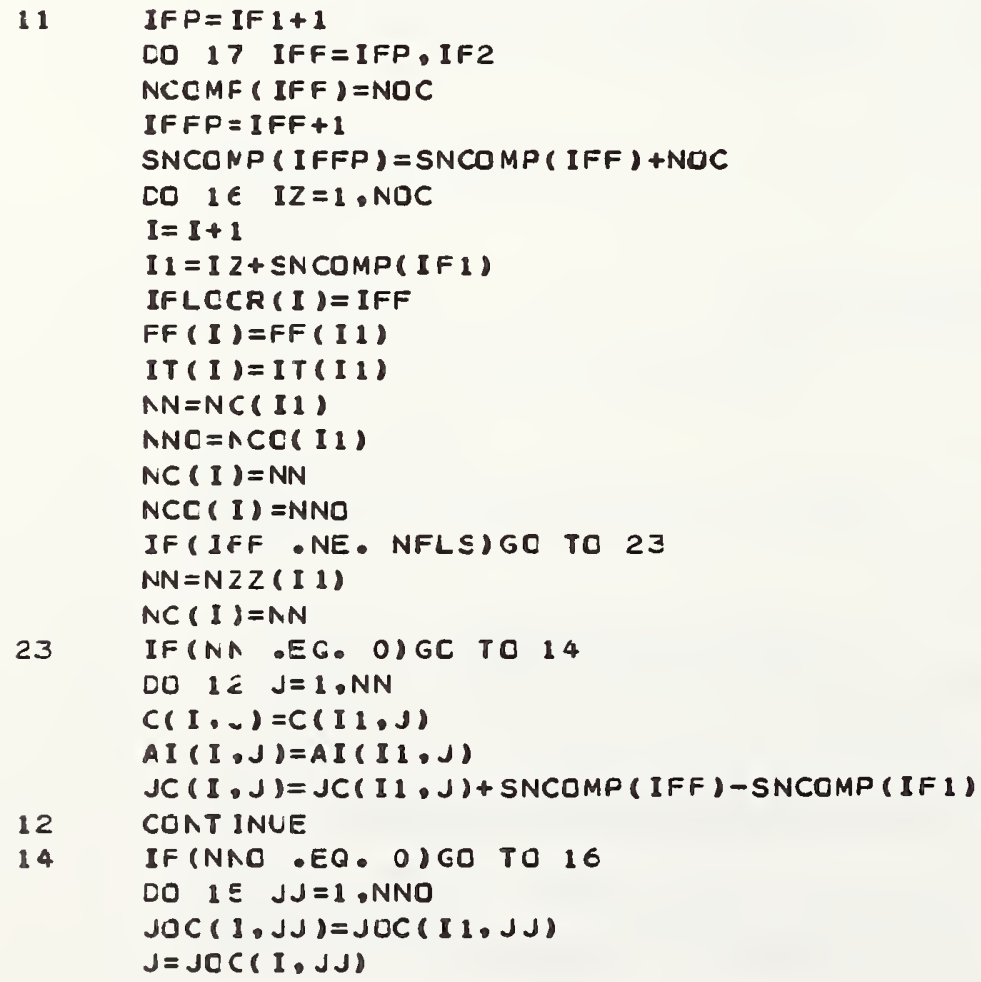




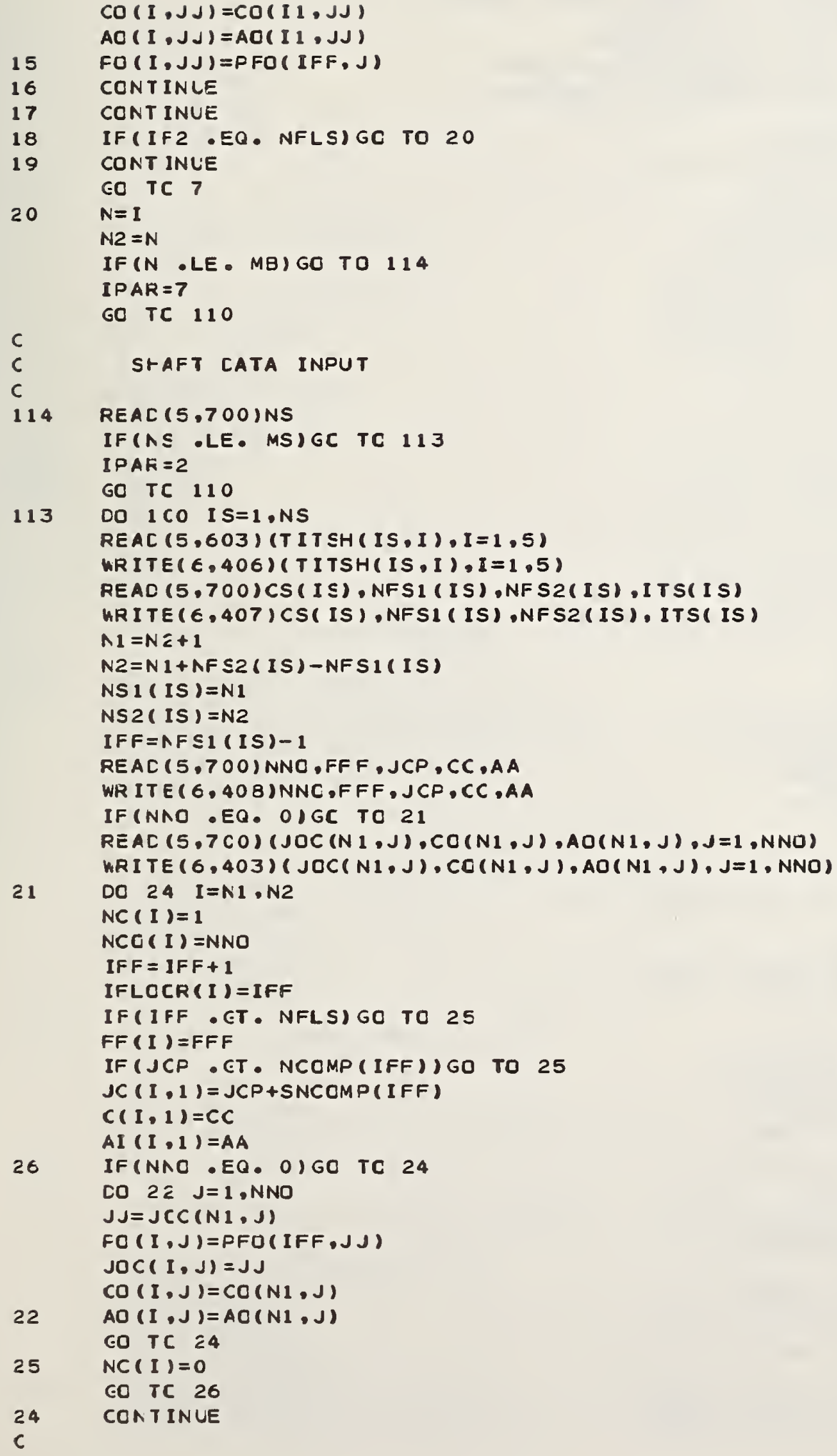

C 
EXCEPTIONS TO GENERAL SHAFT INPUT

NAN = NO. OF EXCEPTIONS

$K E=1$ FOR FF EXCEPTICN

KE $=2$ FOR OUTSIDE CONNECTION

KE $=3$ FOR INTEFNAL CCNNECTICN

REAC $(5,700)$ NNN

IF (NAN.EQ. O) GC TO 100

DO $E S \quad I K=1, N N N$

REAC (5, 700$) \mathrm{KE}$, IFF

WR ITE $(6,409) \mathrm{KE}$, IFF

$I=N S 1$ (IS) +IFF-NFS 1 (IS)

IF (KE .EG. 1) GO TO 41

IF (KE .EQ. 2)GO TO 42

IF (KE $\triangle E G$. 3) GC TO 51

CO TC 104

41 REAC $(5.700)$ FF (I)

WR ITE $(6,410) F F(I)$

GO TC $\in 9$

$\operatorname{REAC}(5.700) \mathrm{J}, \mathrm{CCC}, A A O$

WR ITE $(6,405)$

UR ITE $(6,403) \mathrm{J}, C C D, A A O$

$N N C=A C O(I)$

IF (NAC .EQ. O)GO TO 44

CO $4 \equiv K=1, N N C$

IF $(J \operatorname{LCC}(I, K) \bullet E G . J) G O$ TO 46

43 CONTINUE

$44 \quad N J C=A N C+1$

$A C O(I)=N J C$

$47 \quad P O(I, N J O)=P F O(I F F, J)$

$J O C(1, N J O)=J$

$\operatorname{CO}(I \cdot \cap J O)=C C O$

$A O(I, N J O)=A A O$

GO TC ES

46

NJO $=K$

$K K=K+1$

IF (CCO - NE. O) GC TO 47

$N J C=A N C-1$

$\operatorname{NCC}(I)=N J O$

IF (NJO $-E Q .0) G O T O 69$

DO $45 K=K K$, NNC

$K M=K-1$

$F O(I, K M)=P O(I, K)$

$J O C(I, K M)=J O C(I, K)$

$\operatorname{CO}(I, K M)=\operatorname{CO}(I, K)$

49

$A O(I, K N)=A O(I, K)$

CU TC 69

$\Xi 1$ READ $(5,700) J C P, C C, A A$

WR ITE ( 6.402$)$

URITE $(\epsilon, 403) J C P, C C, A A$

$J=J C F+S N C O M P(I F F)$

$N N=N C($ I)

IF (NA $A G \cdot O)$ GO TO 53

DO $52 \quad K=1, N N$

IF $(J C(I, K), E Q, J) G O$ TO 55

IF (CC .NE. O.) GC TC 53

WR ITE $(\epsilon, 520)$ IS, KE, IFF 


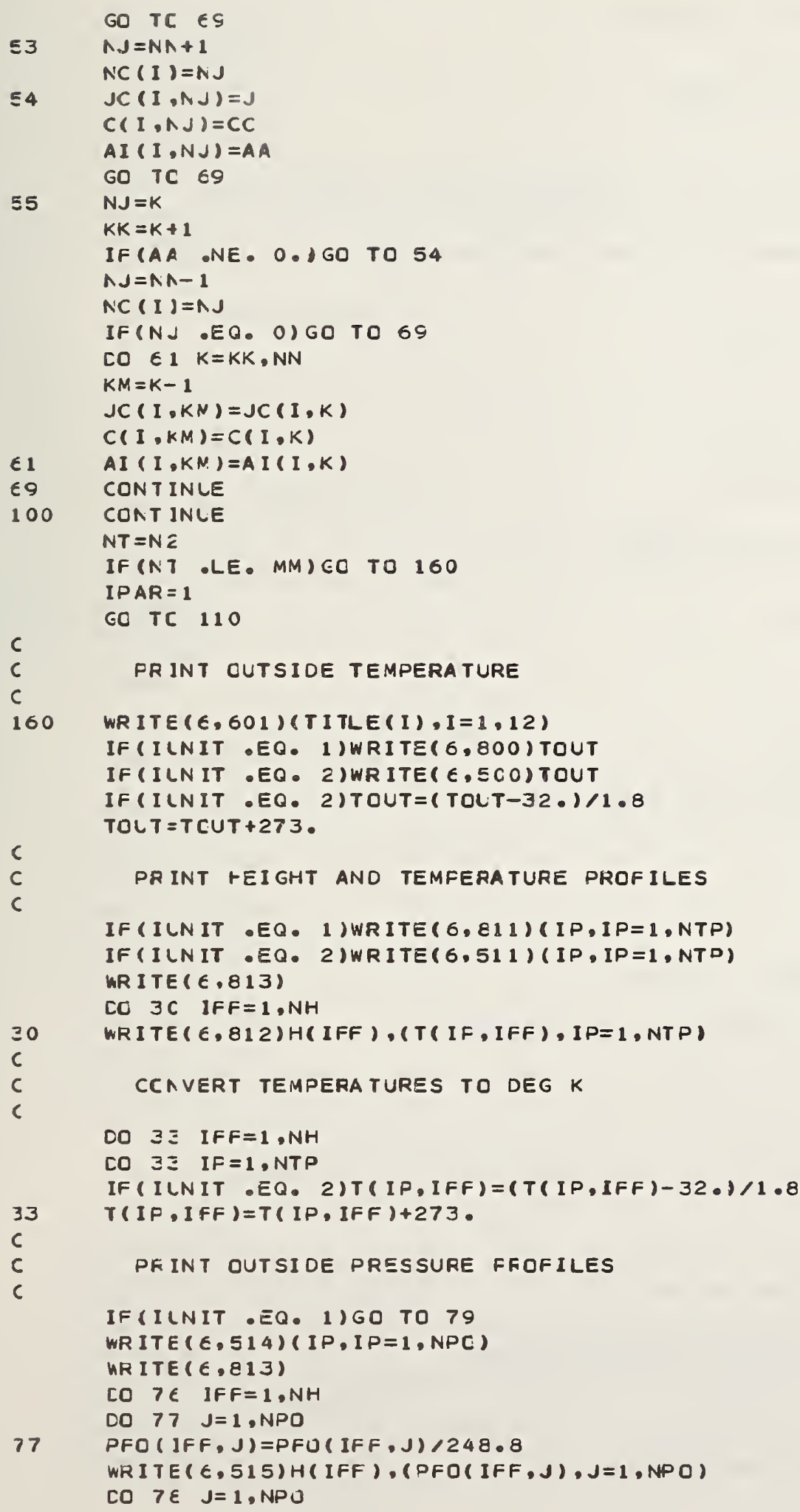

c 


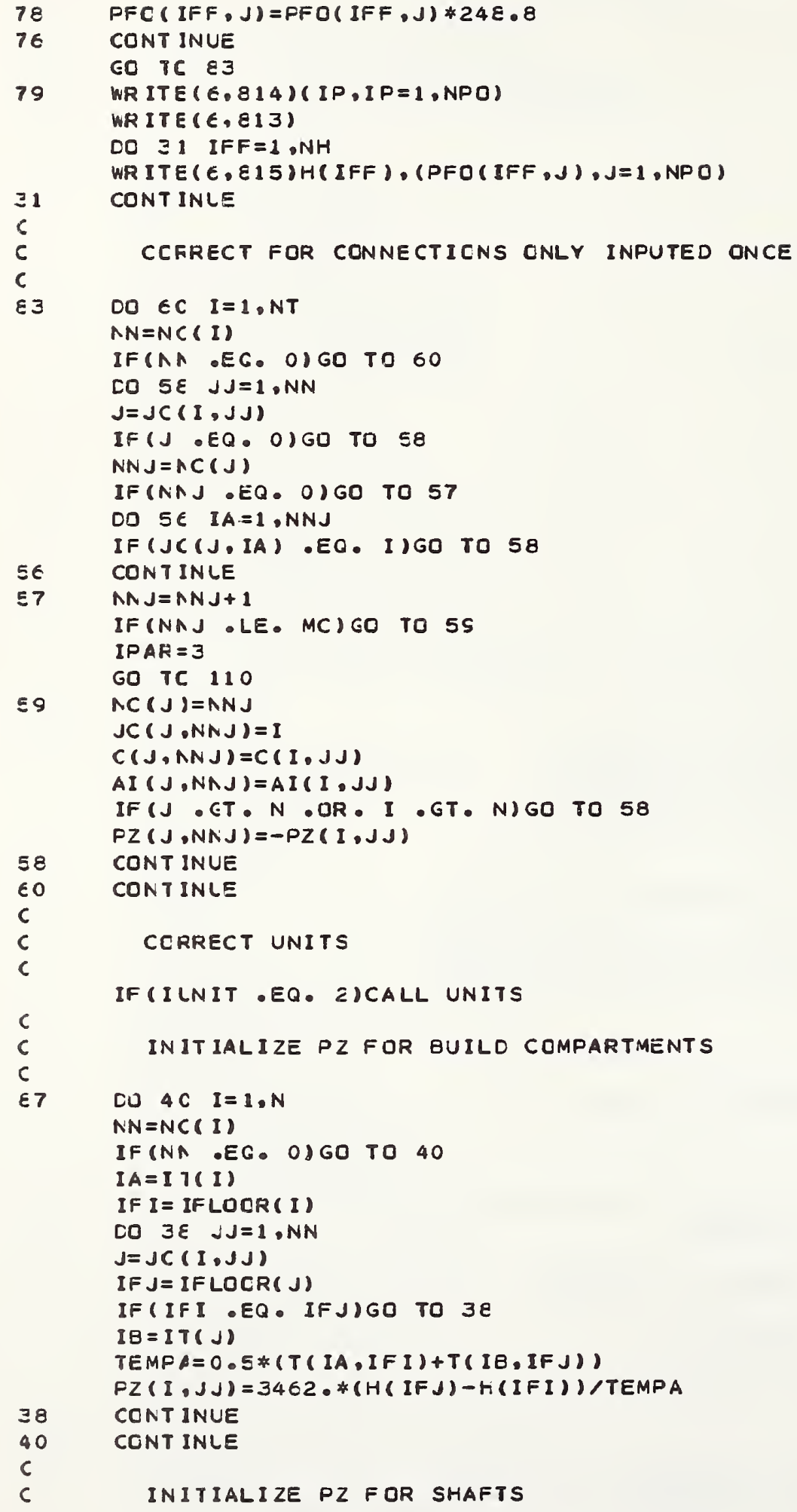

$c$ 


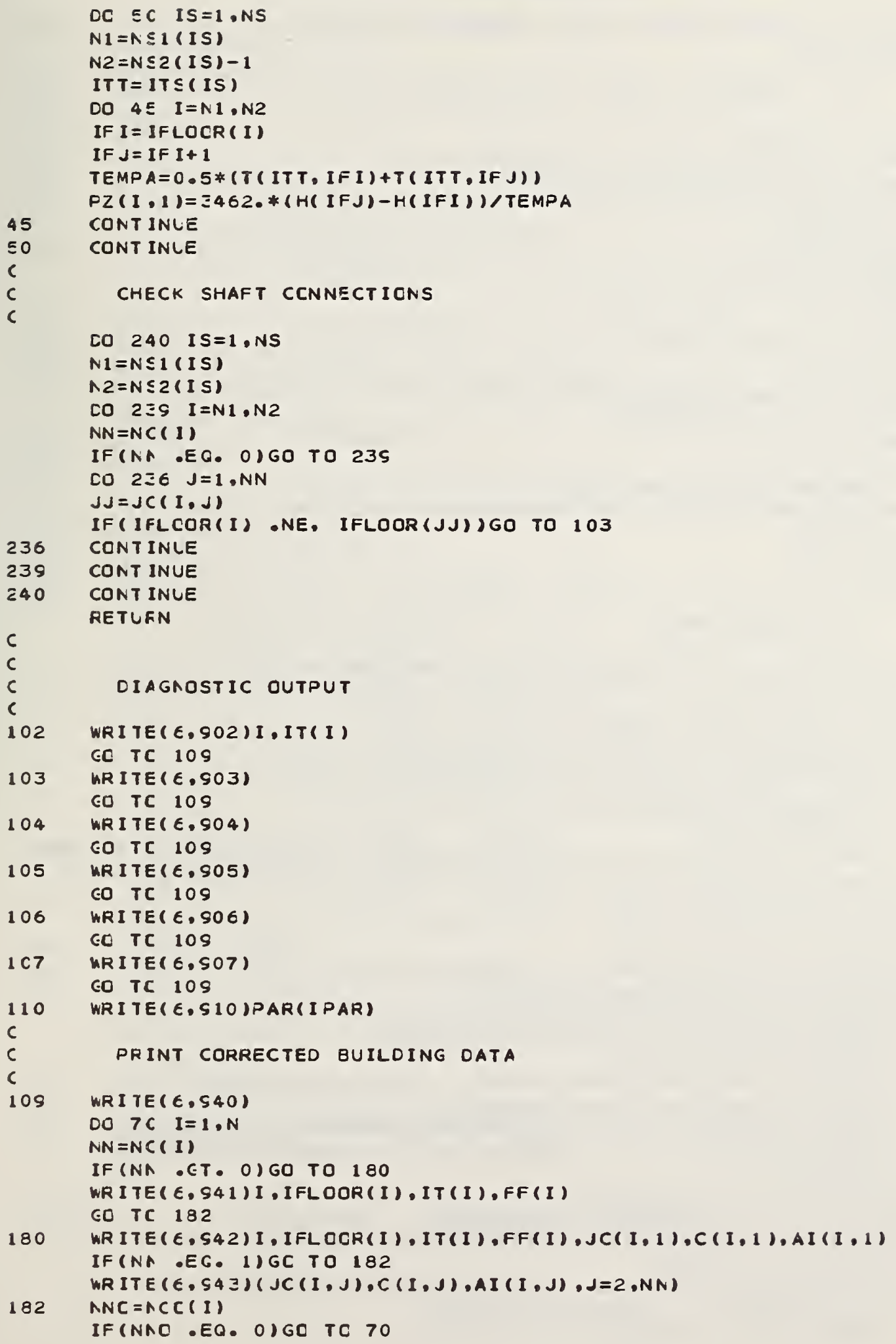




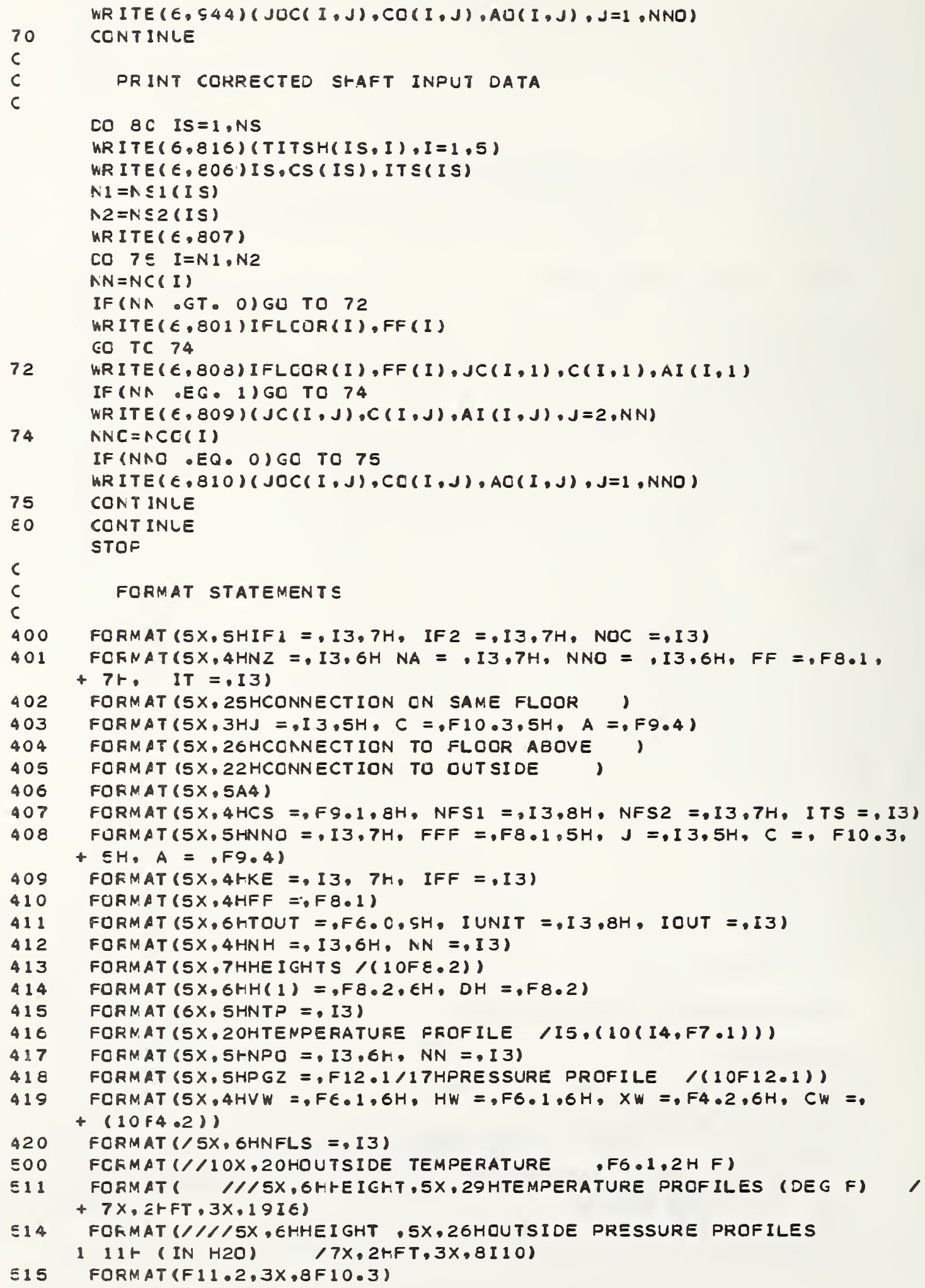


SUBFOUTINE INPUT

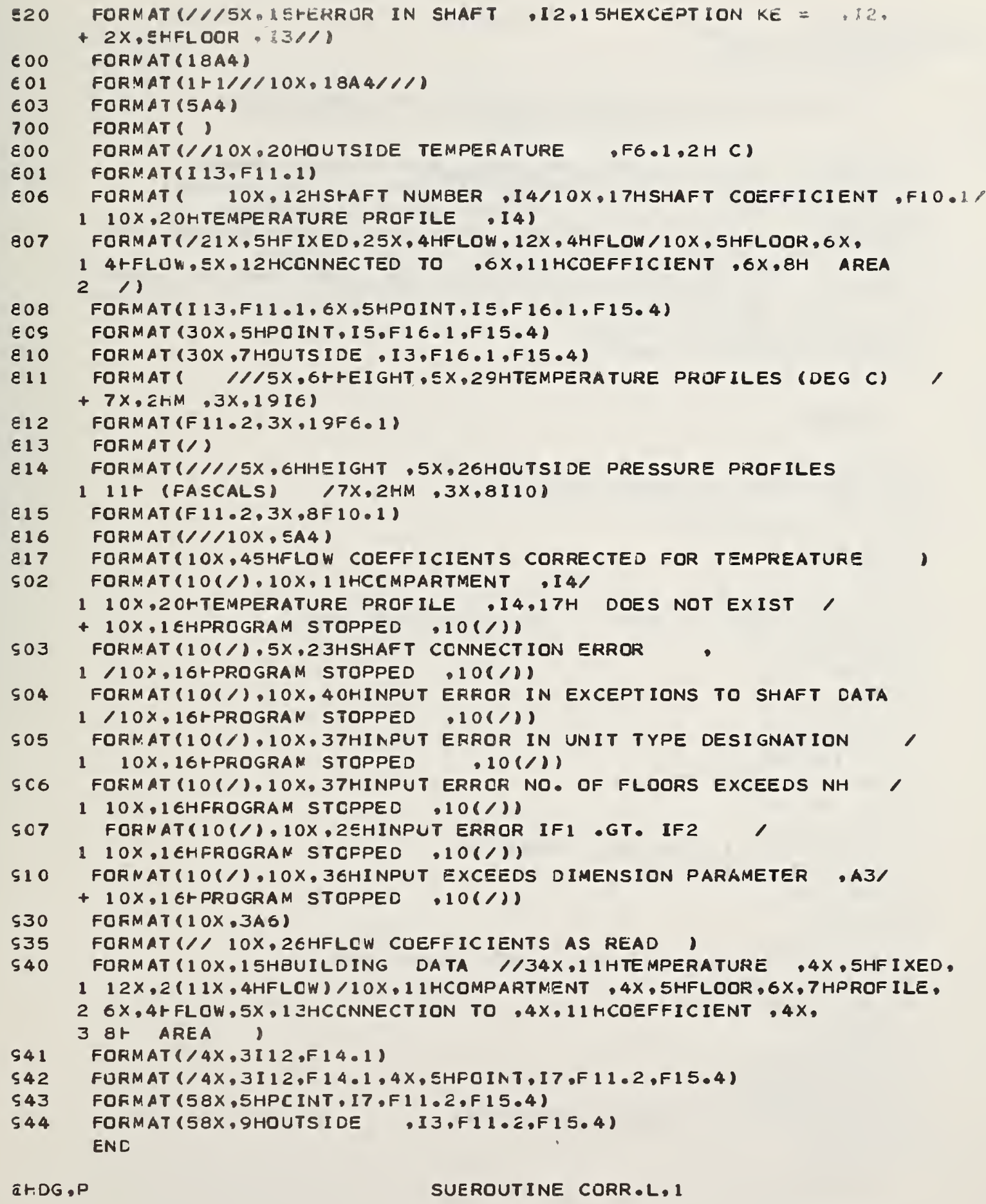




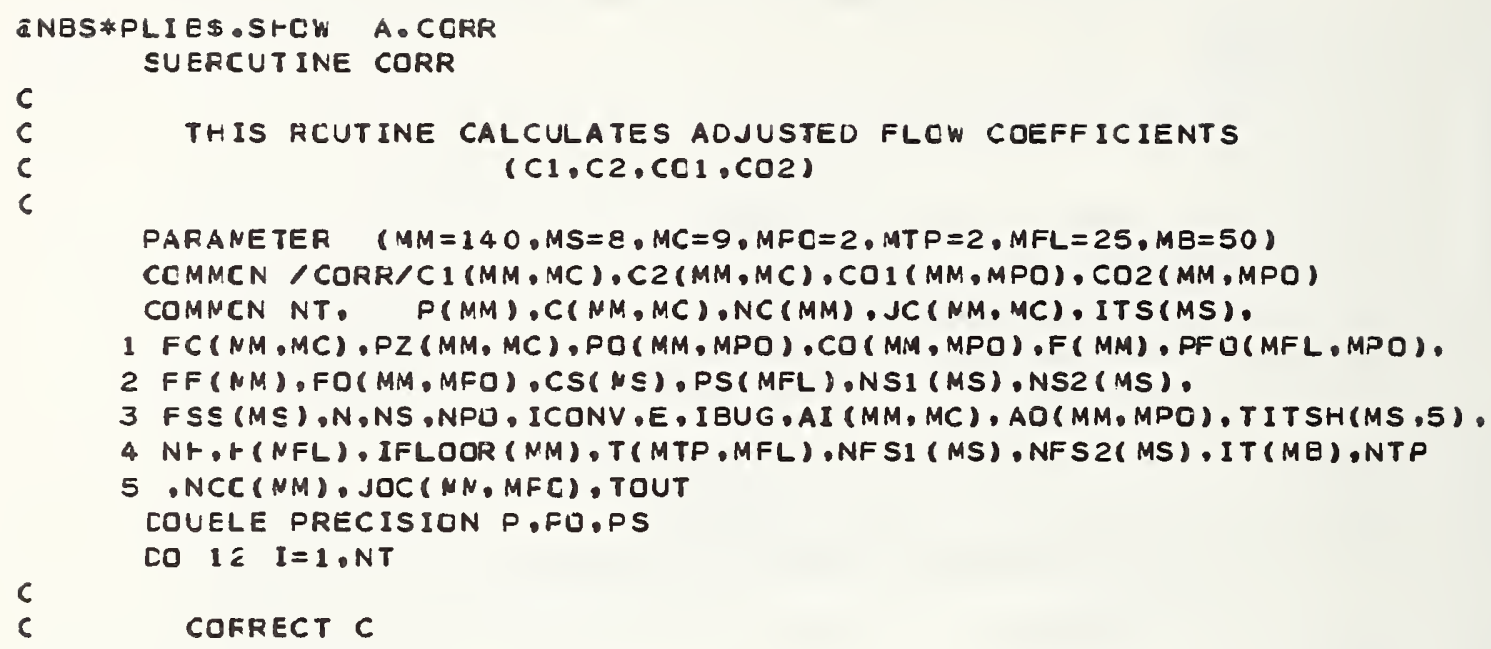

$c$

PARANETER (MM $=140, M S=8, M C=9, M F C=2, M T P=2, M F L=25, M B=50)$

CCMMCN / CORR/C 1 (MM,MC),C2(MM,MC),CO1 (MM,MPO), CO2(MM,MPO) COMNCN NT, $P(M M), C(N M, M C), N C(M M), J C(M M, M C)$, ITS(MS),

$1 F C(N M, M C), P Z(M M, M C), P O(M M, M P O), C O(M M, M P O), F(M M), P F O(M F L, M P O)$,

$2 F F(N M), F O(M M, M F O), C S(M S), P S(M F L), N S 1$ (MS),NS2(MS),

3 FSS (MS), N,NS,NPO, ICONV,E, IBUG, AI (MM, MC), AO(MM,MPO), TITSH(MS,5),

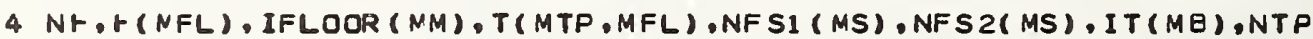

5 , NCC (NM), JOC (MN,MFC), TOUT

COUELE PRECISION P,FU.PS

$c$ CO $1 \approx I=1$.NT

\section{COFRECT C}

PATMCS $=101325$.

$E B=1 C 00 *$ SQRT $(2 *$ PATMOS/287.)/1.2

$N N=N C(I)$

IF (I. ET. N)GO TO 1

$I P=I T(I)$

CO TC 4

CO 2 IS $=1$, NS

IF (I .LE. NS2(IS) .ANC. I .GE. NSI(IS)) GO TO 3

2 CONTINLE

HR. ITE $(\epsilon, 700)$

STOP

3

$I P=I 1 S(I S)$

$I F F=I F L O Q R(I)$

$T 1=T$ (IF, IFF)

IF (NA $E$ EQ O) GO TO 10

CO $9 J=1, N N$

$J J=J(I, J)$

$C 1(I, J)=E B * C(I, J) * A I(I, J) / S Q R T(T 1)$

IF (Jd.GT. N) GO TO 5

$I P=I T(J J)$

co TC 8

LO E IS=1.NS

IF(JJ LLE. NS2(IS) AANC. JJ.GE. NSI(IS)) GOTJ 7

$\epsilon$ CCNT INLE

UR ITE (E, 700)

STOP

$I P=I T S(I S)$

$I F F=1 F \operatorname{LOCR}(\mathrm{JJ})$

$T 2=T$ (IP, IFF )

$C 2(I, J)=\theta B * C(I, J) * A I(I, J) / S$ QRT $(T 2)$

CONT INLE

CERRECT CO

$\wedge N C=\wedge C C(I)$

IF (NAC E EQ O OC TO 12

CO $11 \mathrm{~J}=1$. NNC

$\operatorname{CO} 1(I, J)=B B * C O(I, J) * A O(I, J) / S G R T(T 1)$ 
SUBAOUTINE CORR

$\operatorname{CO} 2(I, J)=B B * C O(I, J) * A C(I, J) / S Q R T(T O U T)$

11 CONTINLE

12 CONTINLE

FETLFN

700

FORMAT $(/ / / 10 X, 36$ HPROGRAM END

arDG, $P$

SUEROUTINE INIT.L,I 


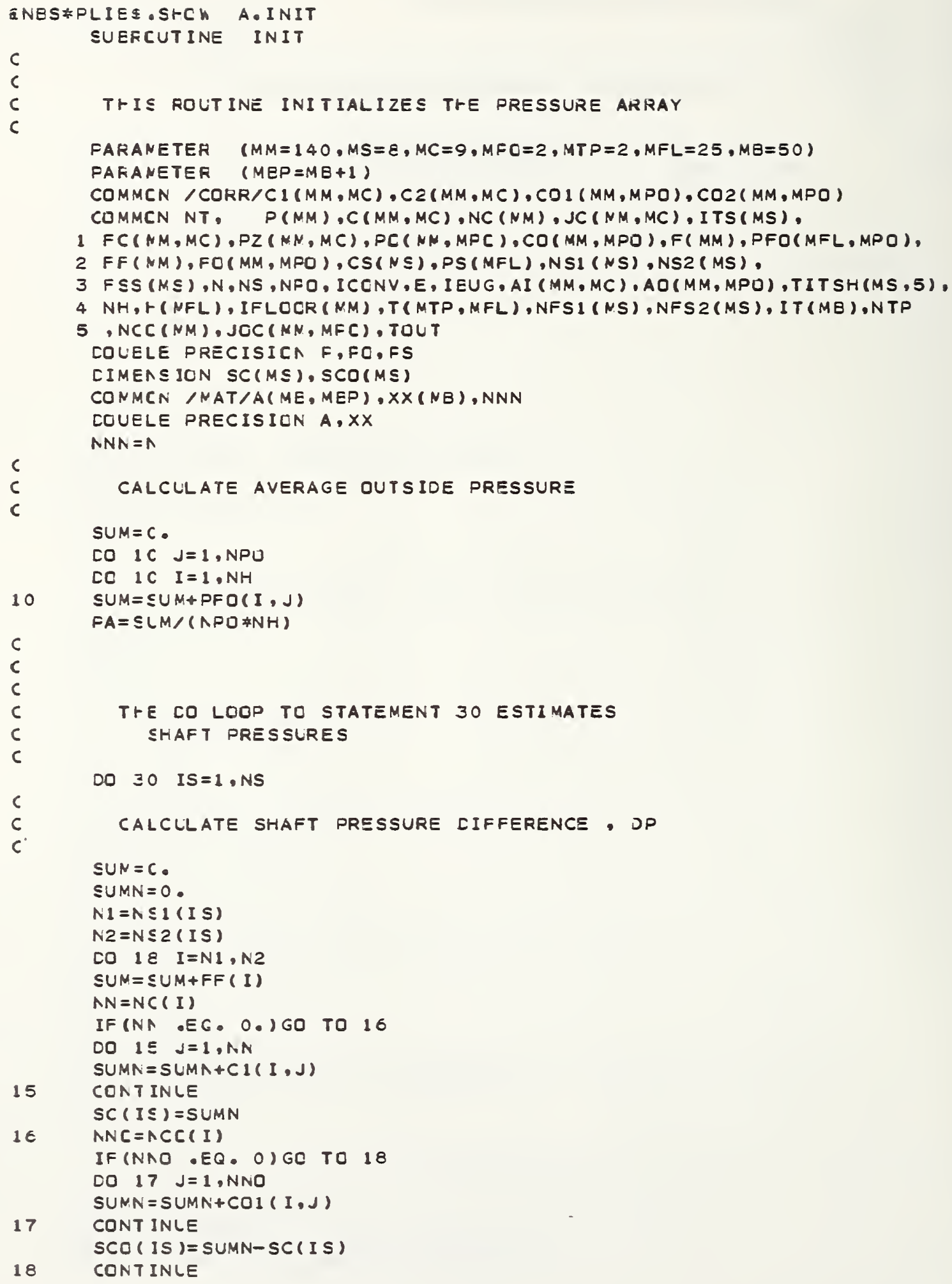




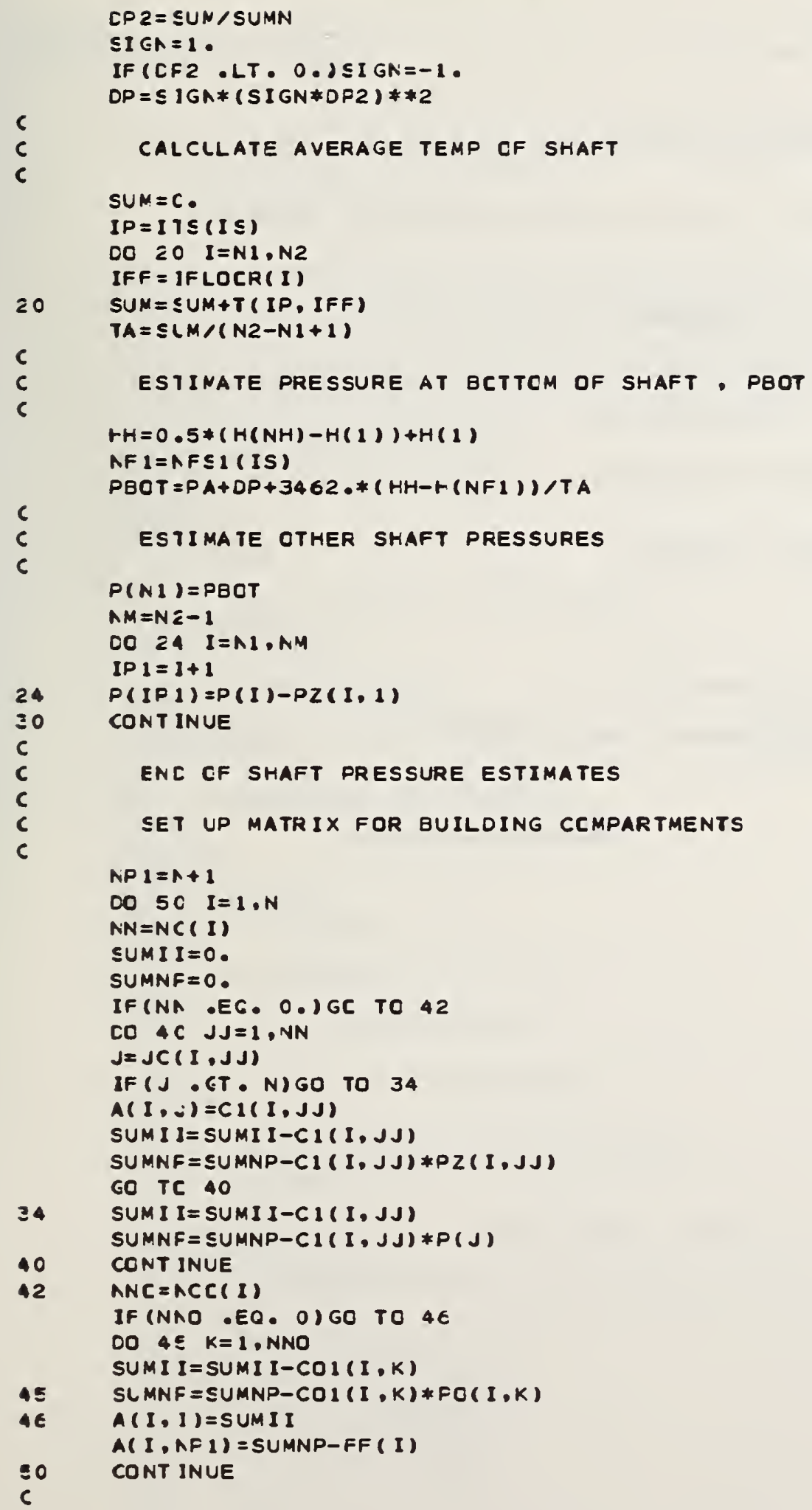


SUBROUTINE INIT

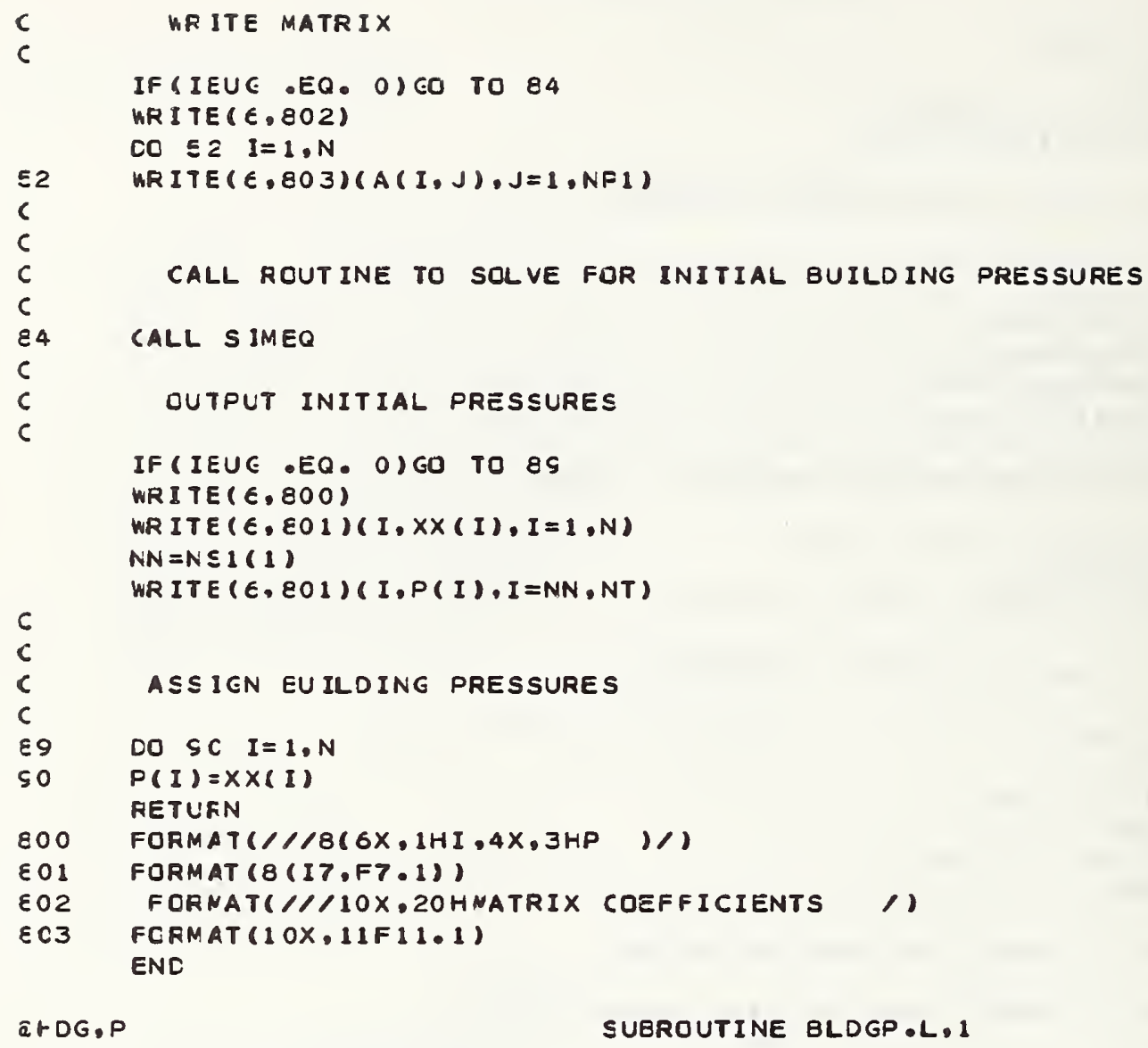




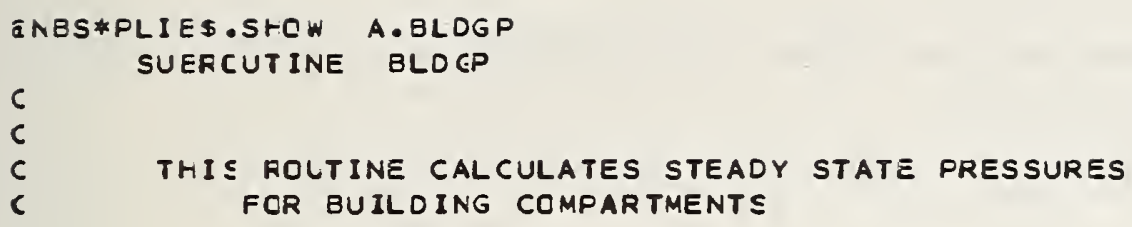




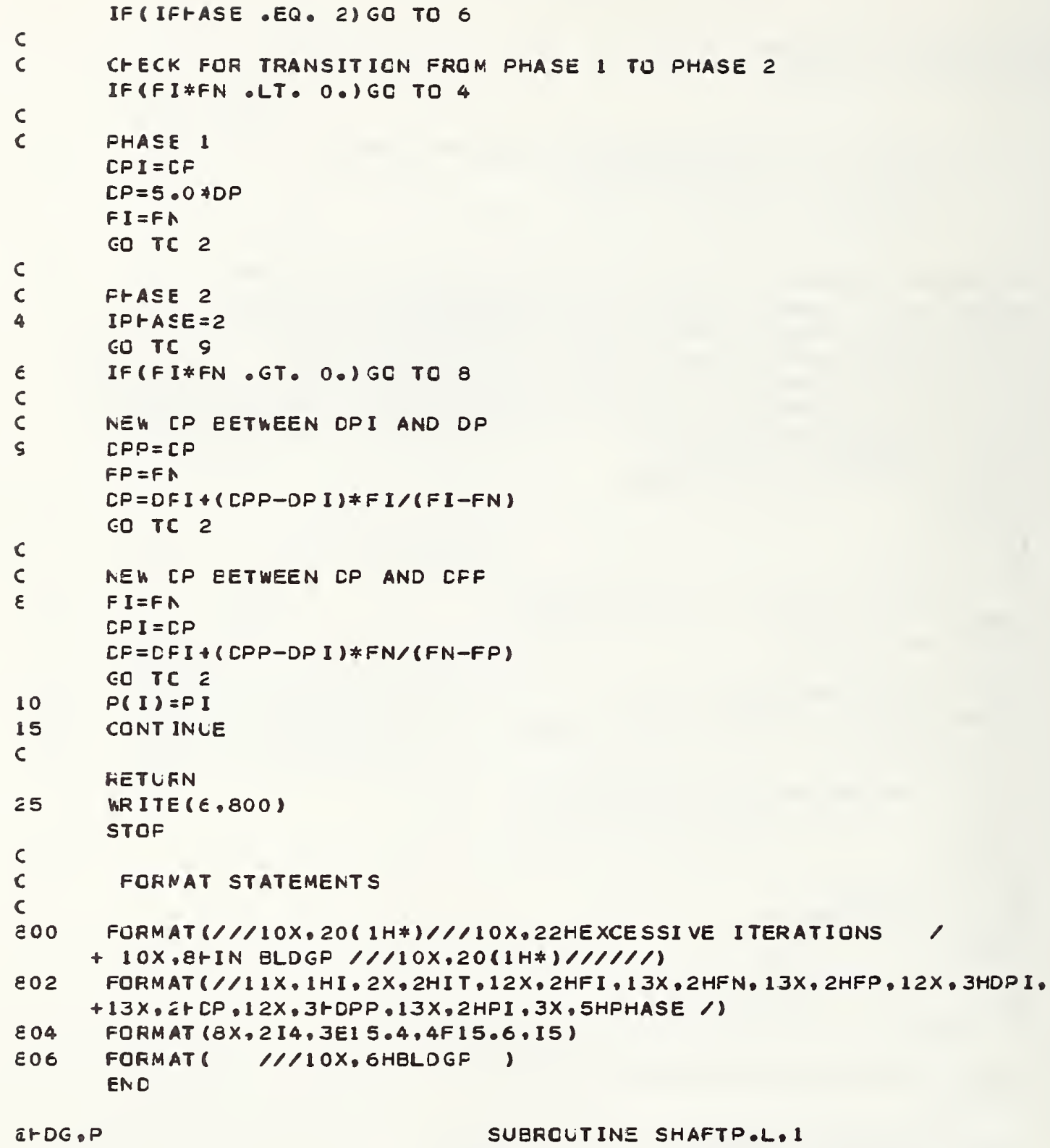




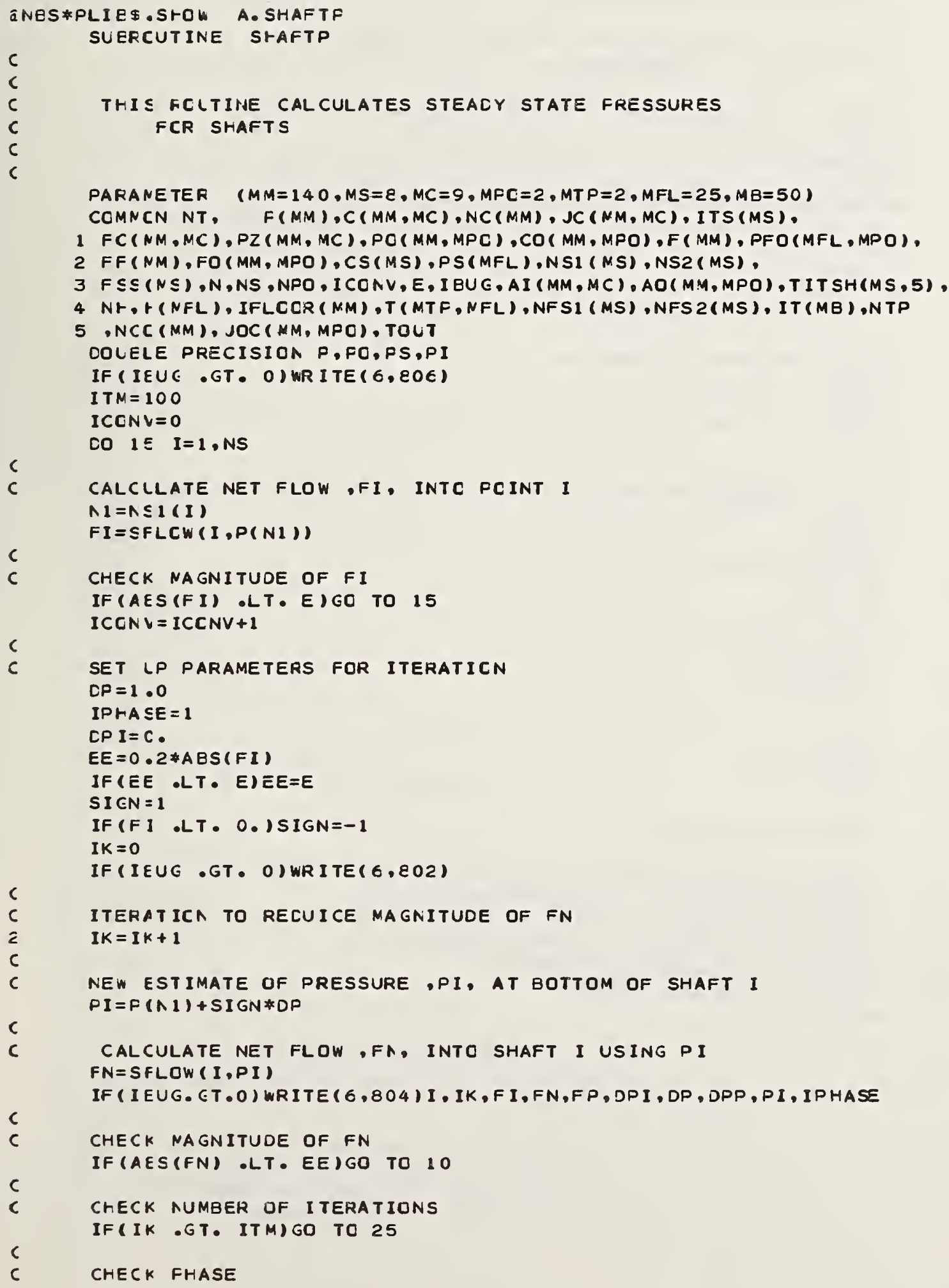




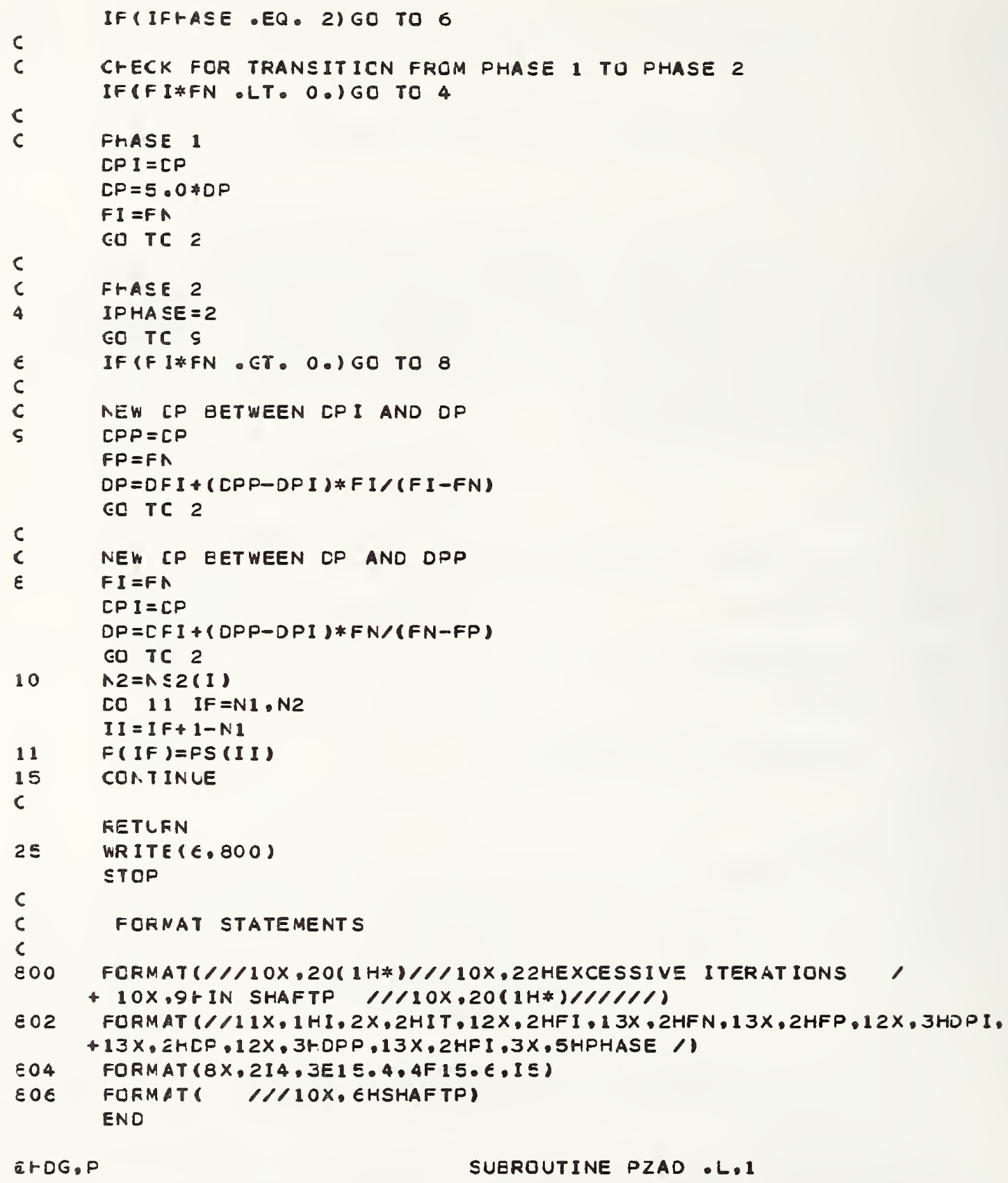




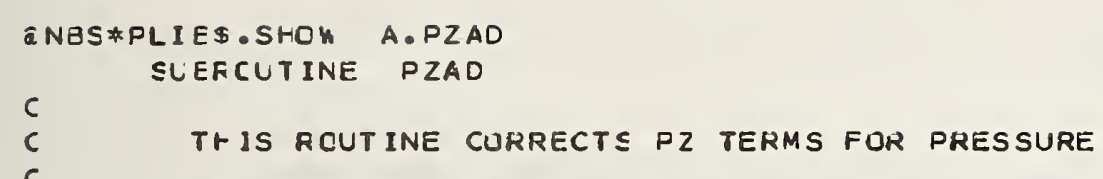




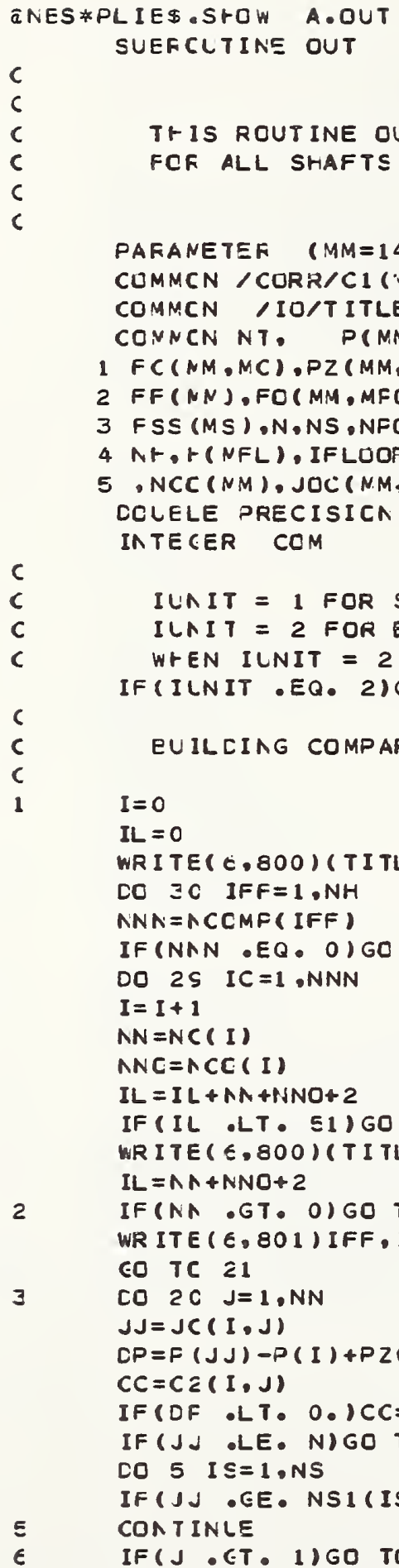

c

c

C

C

C

$c$

c

C

1

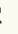


WR ITE $(E, E O 3)(T I T S H(I S, K), K=1, S), D P, C C, A I(I, J), F C(I, J)$

GO TC 20

IF $J=$ IFLOOR(JJ)

CON=JJ-SNCOMP(IFJ)

IF ( $J, E T, 1) G O$ TO 12

WR ITE $(\epsilon, 804)$ IFF,IC,P(I),IT(I),FF(I),IFJ,COM,DP,CC,AI I,I),FC(I,I)

CO TC 20

WR ITE ( 6,805$)$ IF J,COM,DP,CC,AI (I,J),FC (I,J)

EO CONTINUE

a 1 IF (NNO . EO. O)GO TO 29

CO $2 \Xi J=1$, NNO

$J]=J \operatorname{CC}(I, J)$

$C P=P C(I, J)-P(I)$

$C C=C[2(I, J)$

IF (DF .LT. O.) CC=COI I,J)

WRITE $(\epsilon, 806) \mathrm{J}, D P, C C, A O(I, J), F O(I, J)$

WR ITE (, 807$) F(I)$

CONT INUE

MR ITE (E.900)

SFAFT OUTPUT

CO $6 C$ IS $=1$. NS

$N 1=N \leq 1$ (IS)

$N 2=N \leqslant 2$ (IS)

Z2 WRITE(E,EI4)(TITLE (I) I I =1.1E)

WR ITE $(\epsilon, 808)$ (TITSH(IS,K),K=1,5),ITS(IS),CS(IS)

CC 5 C $I=N 1, N 2$

$N N=N C(1)$

IF (NA.GT. O) GO TO 35

WR ITE (, E09) IFLOOR (I),P (I),FF(I)

CO TC 41

35

CO $\triangle C \quad J=1, N N$

$J J=J(I, J)$

$C P=P(J)-P(I)$

$C C=C \approx(I, J)$

IF (DF LT . O. ICC $=C I(I, J)$

IF J = IFLOCR (JJ)

CON=JJ-SNCOMP (IFJ)

IF ( $). G T .1) \mathrm{GO}$ TO 36

WR ITE (6,810)IFLOOR(I),P(I),FF(I),IFJ,COM,DP,CC,AI (I,1),FC(I,1)

GO TC 40

उE WRITE(E.811)IFJ,CCM.DP.CC, AI (I.J),FC(I.J)

40 CONTINUE

41 ANC = ACC (I)

IF (NAO EQ. O) GC TO 50

CO $4 \epsilon J=1$, NNO

$J J=J C C(I, J)$

$C P=F C(I, J)-P(I)$

$C C=C(2(I, J)$

IF (CF .LT. O. ) CC $=C O I(I, J)$

46 WRITE(E.812)JJ,DP.CC.AO(I,J),FO(I,J)

EO CONTINLE

MRITE ( 6.813$)$ FSS(IS)

WR ITE (E. SOO)

EO CONTINLE

GO TC 165

c 
SUEROUTINE OUT

c EUILCING CATA OUTPLT FOR IUNIT $=2$

C

$1 C 7$ WRITE $(\epsilon, 60 \equiv)$ (TITSH(IS,K),K=1,5),DP,CC,AAI,FCCC

$$
\text { GO TC } 120
$$

110 WR ITE ( $\epsilon, 807) F F I$ 


\section{SUBROUTINE OUT}

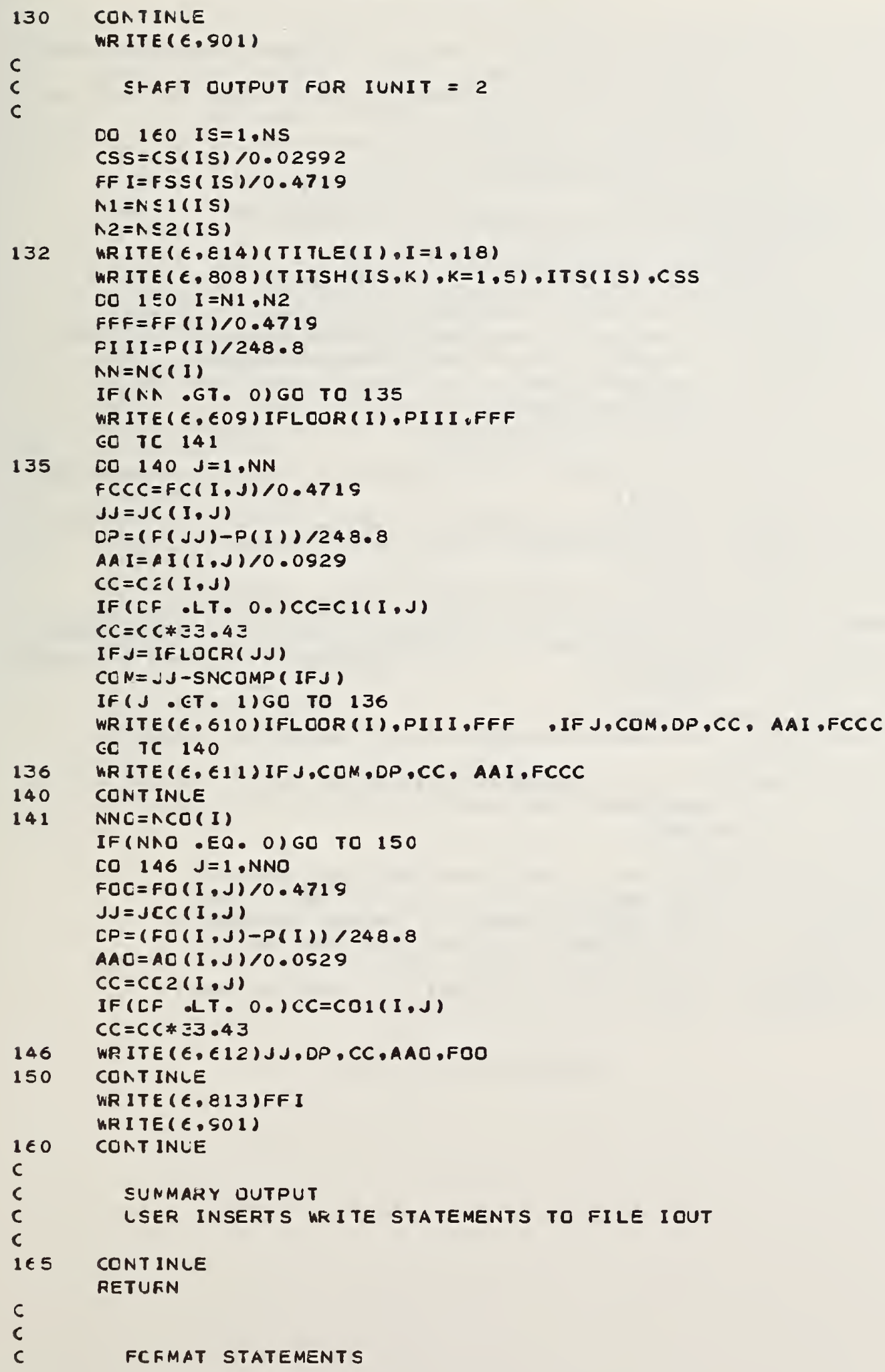


FORM T $(/ 4 X, 13,110, F 13,3,18, F 12,0)$

FORMAT $(/ 4 X, I 3, I 10, F 13,3, I 8, F 12,0,3 X, 5 A 4, F 14,3, F 15,0, F 10,3, F 11,1)$ FOFNAT (5 3X,5A4,F14,3,F1E,C,F10,3,F11.1)

604

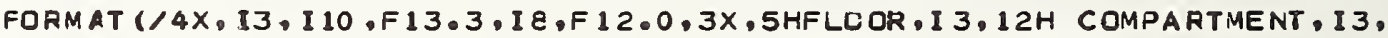

$1 F 11,3, F 15,0, F 10,3, F 11.11$

$\epsilon 05$

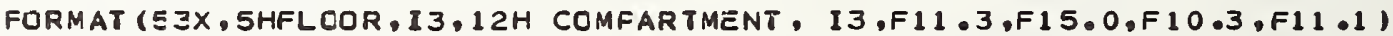
FORMAT $(53 X, 17$ HCUT SIDE DIRECTION,I3,F14,3,F $15,0, F 10,3, F 11$. 1$)$ FORMAT $(4 X, I 3, F 10,3, F 11,0)$

FORMAT $(4 X, I 3, F 10,3, F 11,0,3 X, 5 H F L O O R, I 3,12 H$ COMPARTMENT, I $3, F 11.3$,

$1 F 15,0, F 10,3, F 11.1)$

E 11

612

$\varepsilon 00$

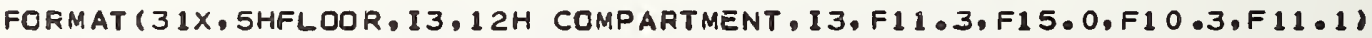
FORMAT ( $31 X, 17$ HOUTSIDE DIRECTION,I3,F $14.3, F 15.0, F 10.3, F 11.1)$

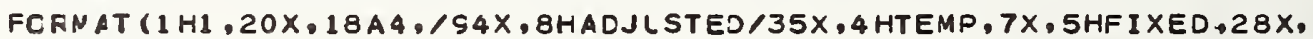

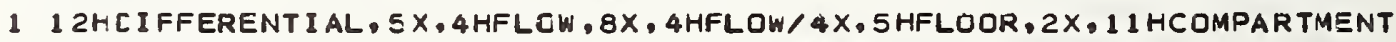

2 . $2 X, 8$, PRESSURE, $2 X, 7 H P R O F I L E, 5 X, 4 H F L O W, 3 X, 16 H C O N N E C T I O N$ TO .

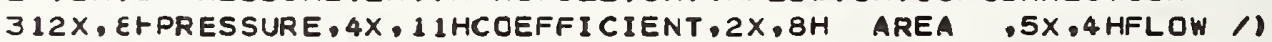
FORMAT $(/ 4 X, I 3, I 10, F 13,1, I 8, F 12,0)$

FORMAT $(/ 4 X, I 3, I 10, F 13,1, I 8, F 12,0,3 X, 5 A 4, F 14,1, F 15,1, F 10,4, F 11,1)$

FOFNAT (53X,5A4,F14,1,F15,1,F 10,4,F11,1)

FORMAT ( $/ 4 X, I 3, I 10, F 13,1, I 8, F 12,0,3 X, 5$ HFLOOR, I 3,12H COMPARTMENT, I 3 ,

$1 F 11.1, F 15,1, F 10,4, F 11.11$

FORMAT (53X,5HFLOOR, I 3.12H COMFARTMENT, I3,F11.1,F15.1.F10.4,F11.1)

FCFMAT (5 $3 X, 17$ HOUT SIDE CIRECTION,I3,F14,1,F $15,1, F 10,4, F 11,1)$ FORMAT ( 1 15X,F8,1,4H NET)

FORMAT $/ / / / 20 X, 5 A 4 / / 20 X, 20 H T E M P E R A T U R E$ PROFILE I I $/ 20 X$,

1 23ト SHAFT FLOW COEFFICIENT OF $10.0 / 172 \times, 8$ HADJUSTED/24X, 5HFIXED,

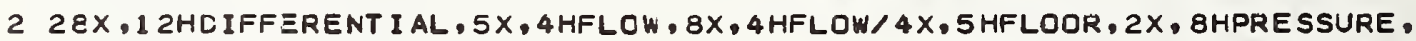

$35 X, 41 F L O W, 3 X, 1 E H C C N N E C T I O N$ TO, $12 X, 8 H P R E S S U R E, 4 X, 11$ HCCEFFICIENT

$4,2 \times, \varepsilon$ AREA $, 5 X, 4$ HFLOW 11

$\varepsilon 09$ FORMAT $(4 X, I 3, F 10,1, F 11.0)$

$\varepsilon 10$

FCRMAT $(4 X, 13, F 10,1, F 11,0,3 X, 5 H F L O O R, I 3,12 H$ COMPART MENT, I $3, F 11.1$,

$1 F 15,1, F 10,4, F 11.1)$

811 FORNAT $(31 \times, 5 H F L O O R, I 3,12 H$ COMPAFTMENT, I 3,F $11,1, F 15,1, F 10,4, F 11.1)$

$\varepsilon 12$

$\varepsilon 13$

814 FORMAT ( $31 \mathrm{X}, 17$ HOUTSIDE DIRECTION II .F $14.1, F 15.1, F 10.4, F 11.1)$ FOFMAT ( $93 \mathrm{X}, F 8,1,4 \mathrm{H}$ NET)

FORMAT ( 1 H1,20X,18A4)

FORMAT (//15X, 'THE FOLLOWING UNITS ARE LSED FOR OUTPUT'

$1 / / 5 X$, PLLW IN LITERS PER SECCND AT 21 DEG C AND 1 ATM"

$2 / 5 X$, PRESSURE IN PASCALS /EX, 'AREA IN METERS SQUARED',

SO1 FORMAT $(/ / /, 5 X$. "THE FOLLOWING UNITS ARE USED FOR OUTPUT'

$1 / / 5 X$, "FLOW IN CFM AT 70 DEG F AND 1 ATM'

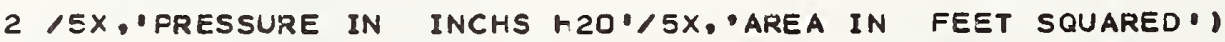
EN D

ăHDG,P

SUERQUTINE UNITS•L.I 


\section{SUBROUTINE UNITS}

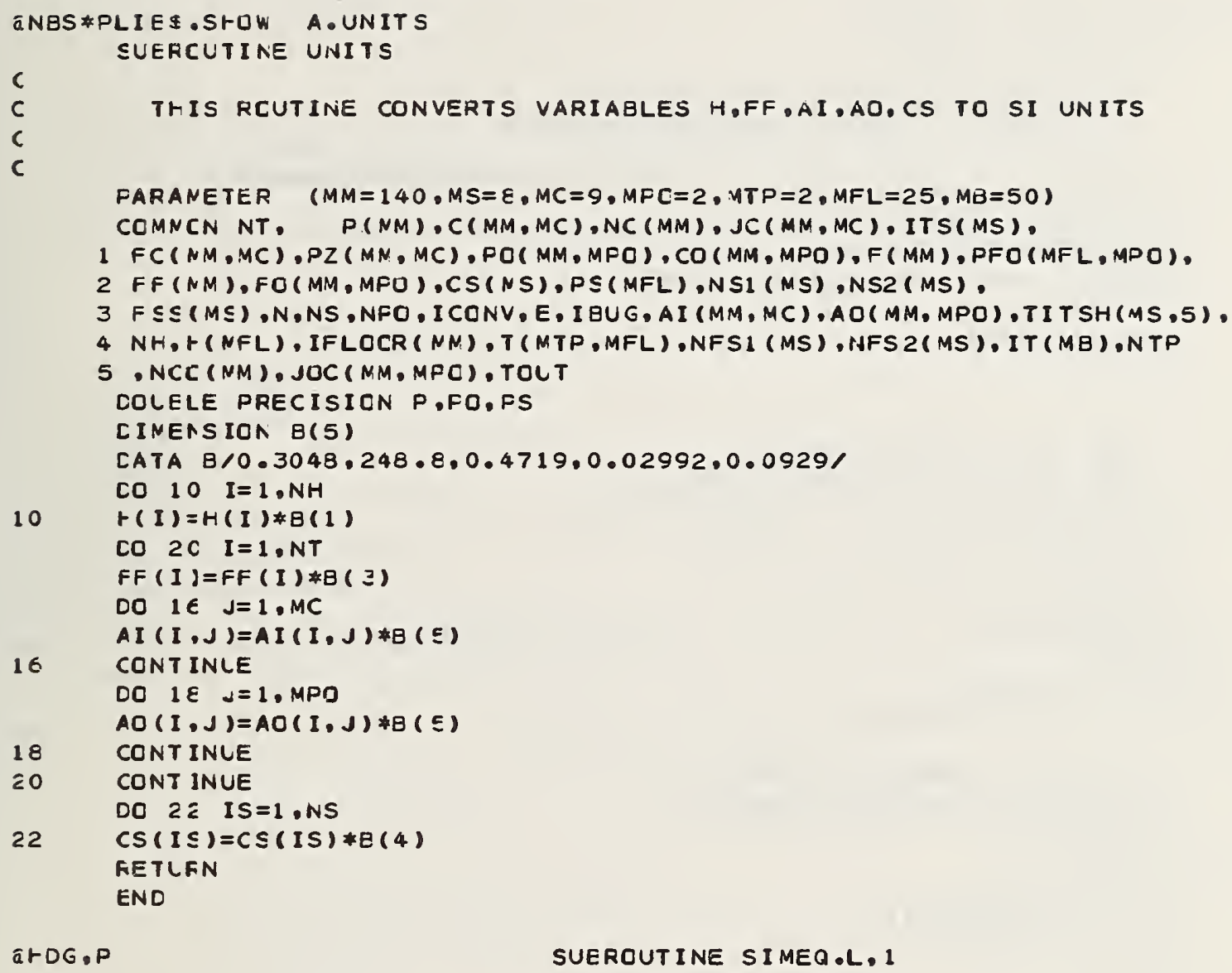

c

C 


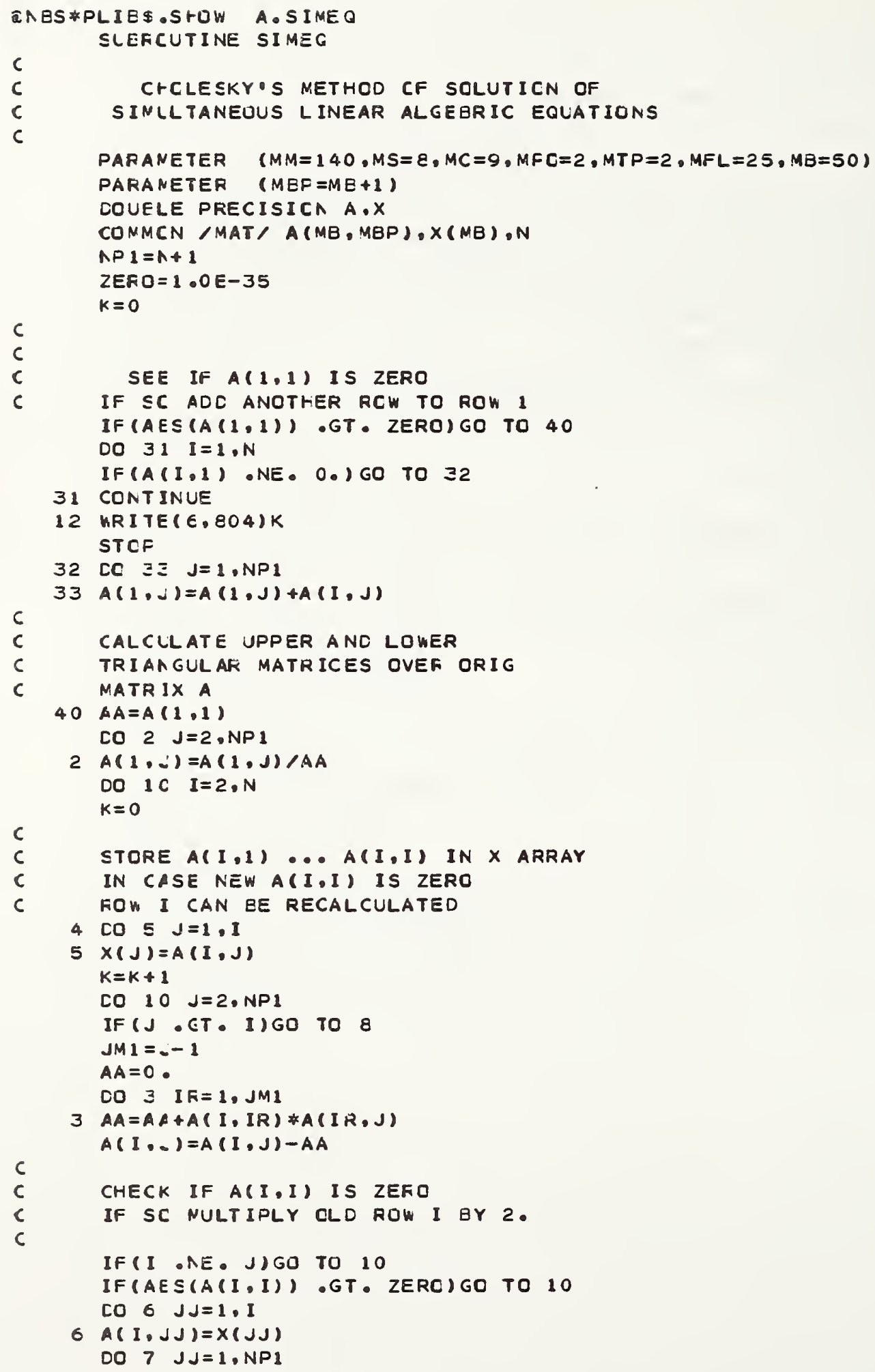




\section{SUBROLTINE SIMEQ}

$7 A(1, j)=2 \cdot * A(I, J)$

IF (K. ET. 3)GO TO 12

GO TC 4

$8 I M 1=1-1$

$A A=0$.

CO $9 I R=1, I M I$

$9 \quad A A=A A+A(I, I R) * A(I R, J)$

$A(I, J)=(A(I, J)-A A) / A(I, I)$

10 CONTINUE

c

ENC CF CALCULATION OF TRIANGULAR MATRICES

c

c

c

EACK MAFD SUBSTITUTICN

$X(N)=A(N, N P 1)$

DO $2 C \quad I I=2, N$

$A A=0$.

$I=N F 1-I I$

$I P 1=1+1$

DO $1 \leqslant J=I P 1, N$

$15 A A=A A+A(I, J) * X(J)$

$20 \times(I)=A(I, N P I)-A A$

C

804 FORMAT $(/ / / / / 10 X, 1$ EHPROGRAM FAILURE, $13 / / / / /)$ END

ar.CG,P

FUNCTION FLOW.L.I 


\section{FUNCTION FLOW}

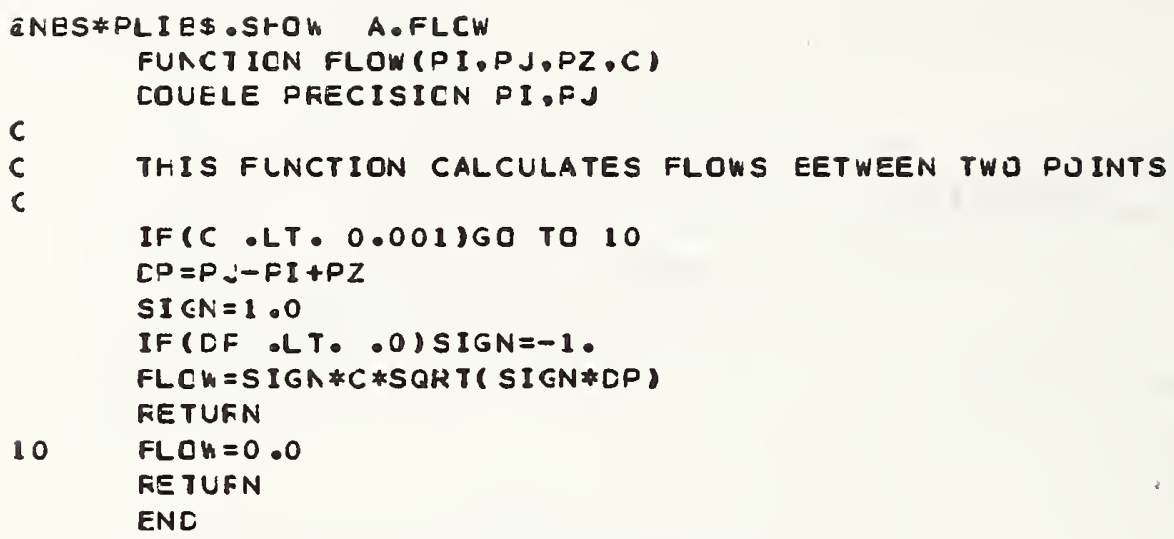

$c$ 


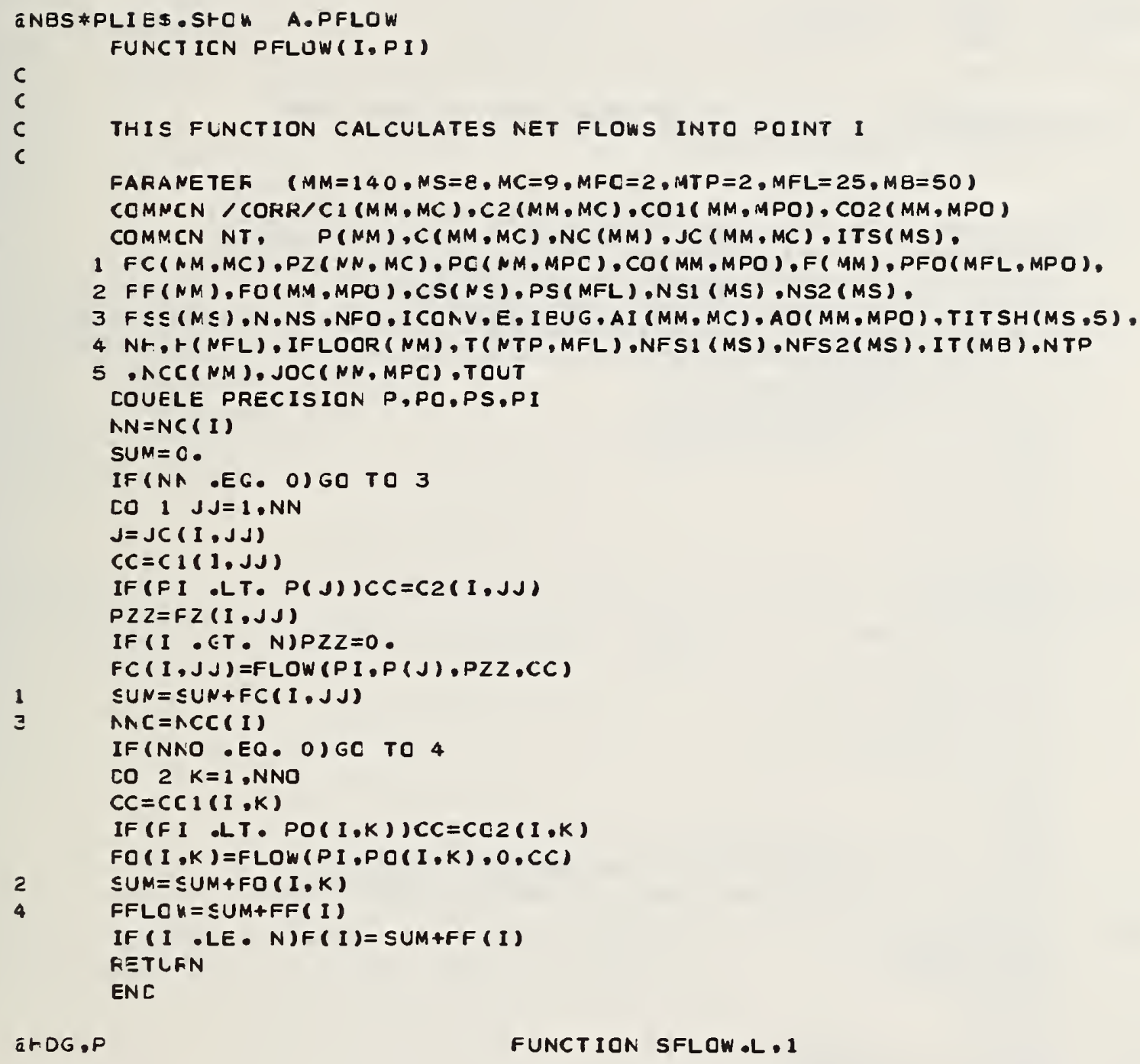




\section{FUNCTION SFLOW}

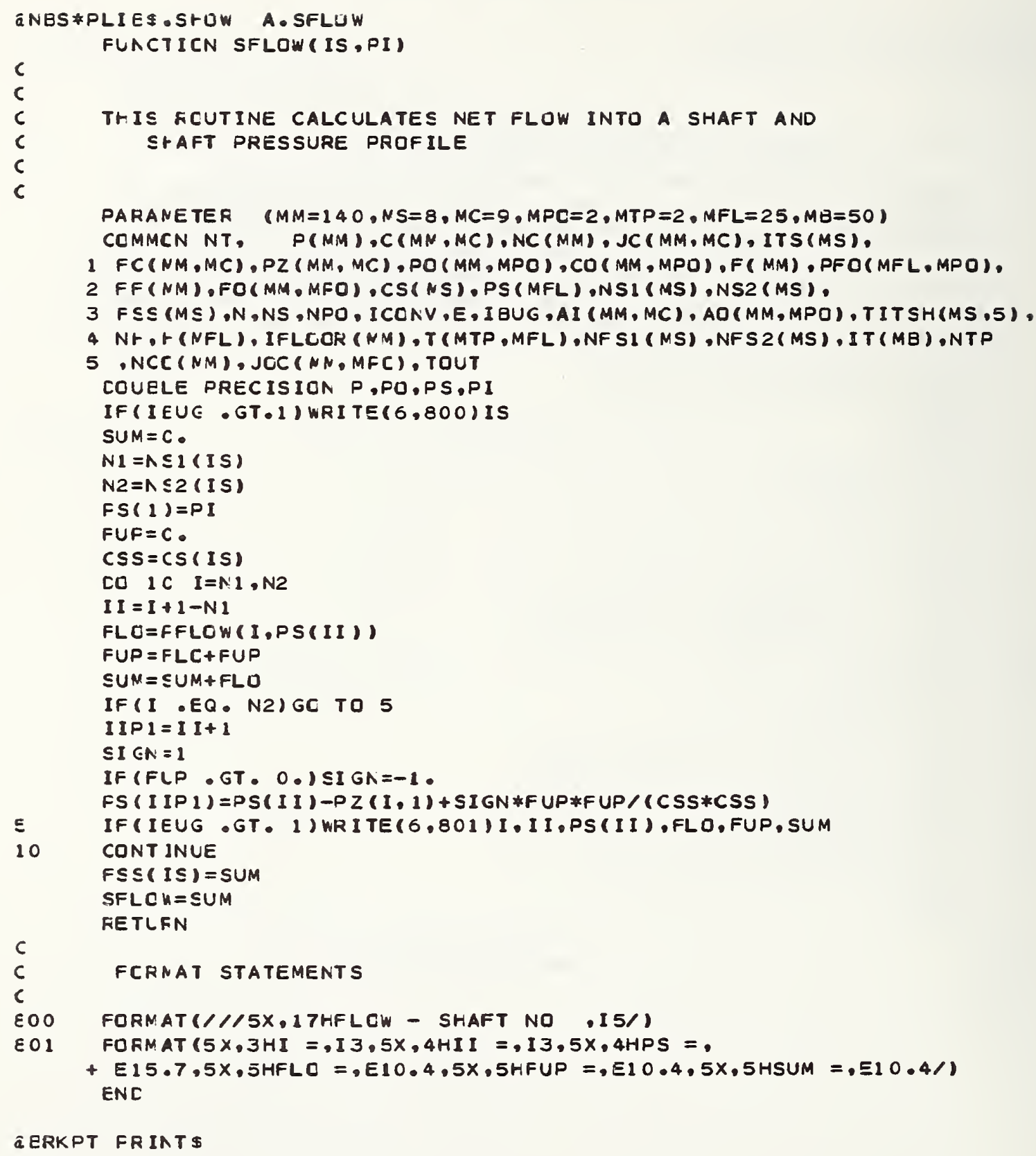




\section{INSTRUCTIONS}

01. Summary Date. Enter date summary prepared. Use Year, Month, Day format: YYMMDD.

02. Summary Prepared By. Enter name and phone number (including area code) of individual who prepared this summary.

03. Summary Action. Mark the appropriate box for new summary, replacement summary or deletion of summary. If this software summary is a replace ment, enter under "Previous Internal Software ID" the internal software identification as reported in item 07 of the original summary, and enter the new internal software identification in item 07 of this form; complete all other items as for a new summary. If a software summary is to be deleted, enter under "Previous Internal Software ID" the internal software identification as reported in item 07 of the original summary; complete only items $01,02,03$ and 11 on this form.

04. Software Date. Enter date software was completed or last updated. Use Year, Month, Day format: YYMMDD.

05. Software Title. Make title as descriptive as possible.

06. Short Title. (Optional) Enter commonly used abbreviation or acronym which identifies the software.

07. Internal Software ID. Enter a unique identification number or code.

08. Software Type. Mark the appropriate box for an Automated Data System (set of computer programs), Computer Program, or Subroutine/Module, whichever best describes the software.

09. Processing Made. Mark the appropriate box for an Interactive, Batch, or Combination mode, whichever best describes the software.

10. Application Area.

General: Mark the appropriate box which best describes the general area of application from among:

Computer Systems Support/Utility

Management/Business

Scientific/Engineering

Process Control

Bibliographic/Textual

Other

Specific: Specify the sub-area of application; e.g.: "COBOL optimizer" if the general area is "Computer Systems Support/Utility"; "Payroll" if the general area is "Management/Business"; etc. Elaborate here if the general area is "Other."

11. Submitting Organization and Address. Identify the organization responsible for the software as completely as possible, to the Branch or Division level, but including Agency, Department (Bureau/Administration), Service, Corporation, Commission, or Council. Fill in complete mailing address, including mail code, street address, city, state, and ZIP code.

12. Technical Contact(s) and Phone: Enter person(s) or office(s) to be contacted for technical information on subject matter and/or operational aspects of software. Include telephone area code. Provide organization name and malling address, if different from that in item 11.

13. Narrative. Describe concisely the problem addressed and methods of solution. Include significant factors such as special operating system modifications, security concerns, relationships to other software, input and output media, virtual memory requirements, and unique hardware features. Cite references, if appropriate.

14. Keywords. List significant words or phrases which reflect the functions, applications and features of the software. Separate entries with semicolons.

15. Computer Manufacturer and Model. Identify mainframe computer(s) on which software is operational.

16. Computer Operating System. Enter name, number, and release under which software is operating. Identify enhancements in the Narrative (item 13).

17. Programing Language(s). Identify the language(s) in which the software is written, including version; e.g., ANSI COBOL, FORTRAN V, SIMSCRIPT II.5, SLEUTH II.

18. Number of Source Program Statements. Include statements in this software, separate macros, called subroutines, etc.

19. Computer Memory Requirements. Enter minimum internal memory necessary to execute software, exclusive of memory required for the operating system. Specify words, bytes, characters, etc., and number of bits per unit. Identify virtual memory requirements in the Narrative (item 13).

20. Tape Drives. Identify number needed to operate software. Specify, if critical, manufacturer, model, tracks, recording density, etc.

21. Disk/Drum Units. Identify number and size (in same units as "Memory"-item 19) needed to operate software. Specify, if critical, manufacturer, model, etc.

22. Terminals. Identify number of terminals required. Specify, if critical, type, speed, character set, screen/line size, etc.

23 Other Operational Requirements. Identify peripheral devices, support software, or related equipment not indicated above, e.g., optical character devices, facsimile, computer-output microfilm, graphic plotters.

24. Software Availability. Mark the appropriate box which best describes the software availability from among: Available to the Public, Limited Availability (e.g.: for government use only), and For-In-house Use Only. If the software is "Available", include a mail or phone contact point, as well as the price and form in which the software is available, if possible.

25. Documentation Availability. Mark the appropriate box which best describes the documentation availability from among: Available to the Public, Inadequate for Distribution, and For li1-house Use Only. If documentation is "Available", include a mail or phone contact point, as well as the price and form in which the documentation is available, if possible. If documentation is presently "Inadequate", show the expected availability date.

26. For Submitting Organization Use. This area is provided for the use of the organization submitting this summary. It may contain any information deemed useful for internal operation. 
NBS-114A (REV. 2-80)

U.S. DEPT. OF COMM.

BIBLIOGRAPHIC DATA

1. PUBLICATION OR

REPORT NO.

NBSIR 82-2512

2. Performing Organ. Report Nod 3. Publication Date

SHEET (See instructions)

4. TITLE AND SUBTITLE

A COMPUTER PROGRAM FOR ANALYSIS OF SMOKE CONTROL SYSTEMS

5. $A U T H O R(S)$

John H. Klote

6. PERFORMING ORGANIZATION (If joint or other than NBS, see instructions)

7. Contract/Grant No.

NATIONAL BUREAU OF STANDARDS

DEPARTMENT OF COMMERCE

WASHINGTON, D.C. 20234

8. Type of Report \& Period Covered

Final Report

9. SPONSORING ORGANIZATION NAME AND COMPLETE ADDRESS (Street, City, Stote, ZIP)

Department of Health and Human Services

Washington, D.C. 20201

10. SUPPLEMENTARY NOTES

[] Document describes a computer program; SF-185, FIPS Software Summary, is attached.

11. ABSTRACT (A 200-word or less factual summary of most significant information. If document includes a significant bibliography or literature survey. mention it here)

This paper describes a computer program developed to analyze systems intended to control smoke in building fires. These systems include pressurized stairwells, pressurized elevator shafts, zone smoke control systems, and pressurized corridors. This program calculates air flows and differential pressures throughout a building in which a smoke control system is operating. The basic assumptions and limitations of the program are also discussed. The appendices contain a program listing and examples.

12. KEY WORDS (Six to twelve entries; alphabetical order: capitalize only proper names; and separate key words by semicolons) Air movement; computer programs; egress; elevator shafts; escape means; modeling; pressurization; simulation; smoke control; stairwells

13. AVAILABILITY

[xखUnlimited

$\square$ For Official Distribution. Do Not Release to NTIS

14. NO. OF PRINTED PAGES

$\square$ Order From Superintendent of Documents, U.S. Government Printing Office, Washington, D.C. 20402.

15. Price

[ $]$ Order From National Technical Information Service (NTIS), Springfield, VA. 2216I 


